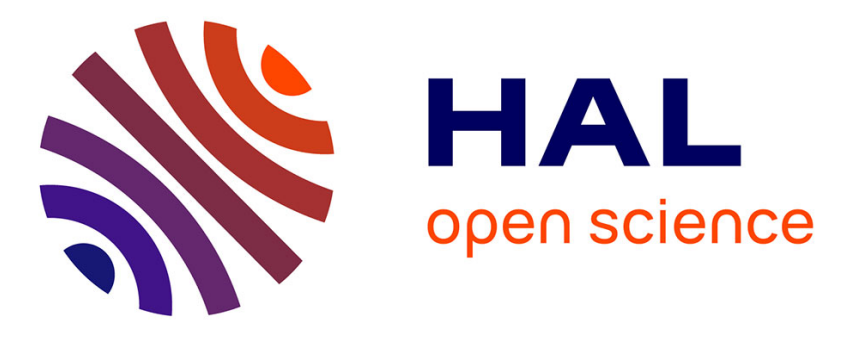

\title{
Alkylthio-tetrasubstituted $\mu$-Nitrido Diiron \\ Phthalocyanines: Spectroelectrochemistry, Electrical Properties, and Heterojunctions for Ammonia Sensing
}

Zeynel Şahin, Rita Meunier-Prest, Fabienne Dumoulin, Ümit İşci, Marcel Bouvet

\section{To cite this version:}

Zeynel Şahin, Rita Meunier-Prest, Fabienne Dumoulin, Ümit İşci, Marcel Bouvet. Alkylthiotetrasubstituted $\mu$-Nitrido Diiron Phthalocyanines: Spectroelectrochemistry, Electrical Properties, and Heterojunctions for Ammonia Sensing. Inorganic Chemistry, 2020, 59 (2), pp.1057 - 1067. 10.1021/acs.inorgchem.9b02520 . hal-03028349

\section{HAL Id: hal-03028349 \\ https://hal.science/hal-03028349}

Submitted on 27 Nov 2020

HAL is a multi-disciplinary open access archive for the deposit and dissemination of scientific research documents, whether they are published or not. The documents may come from teaching and research institutions in France or abroad, or from public or private research centers.
L'archive ouverte pluridisciplinaire $\mathbf{H A L}$, est destinée au dépôt et à la diffusion de documents scientifiques de niveau recherche, publiés ou non, émanant des établissements d'enseignement et de recherche français ou étrangers, des laboratoires publics ou privés. 


\section{Alkylthio-tetrasubstituted $\mu$-Nitrido Diiron Phthalocyanines: Spectroe- lectrochemistry, Electrical Properties and Heterojunctions for Ammo- nia Sensing}

Zeynel Şahin§, Rita Meunier-Prest ${ }^{\dagger}$, Fabienne Dumoulin§, Ümit Isci§*, Marcel Bouvet ${ }^{+*}$

The $\mu$-nitrido diiron phthalocyanines complexes are synthesized and studied by a spectroelectrochemical investigation at all the redox states. Electrical properties of $\mu$-nitrido dimetallo-macrocyclic complexes are determined. For the first time. Their low HOMO-LUMO gap relates to first oxidation and reduction steps that occur at the metal centers, whereas the intermolecular electron transfer deals with redox states on phthalocyanine rings. Combined with the lutetium bisphthalocyanine they lead to heterojunctions suitable to detect ammonia in the ppm range, at room temperature.

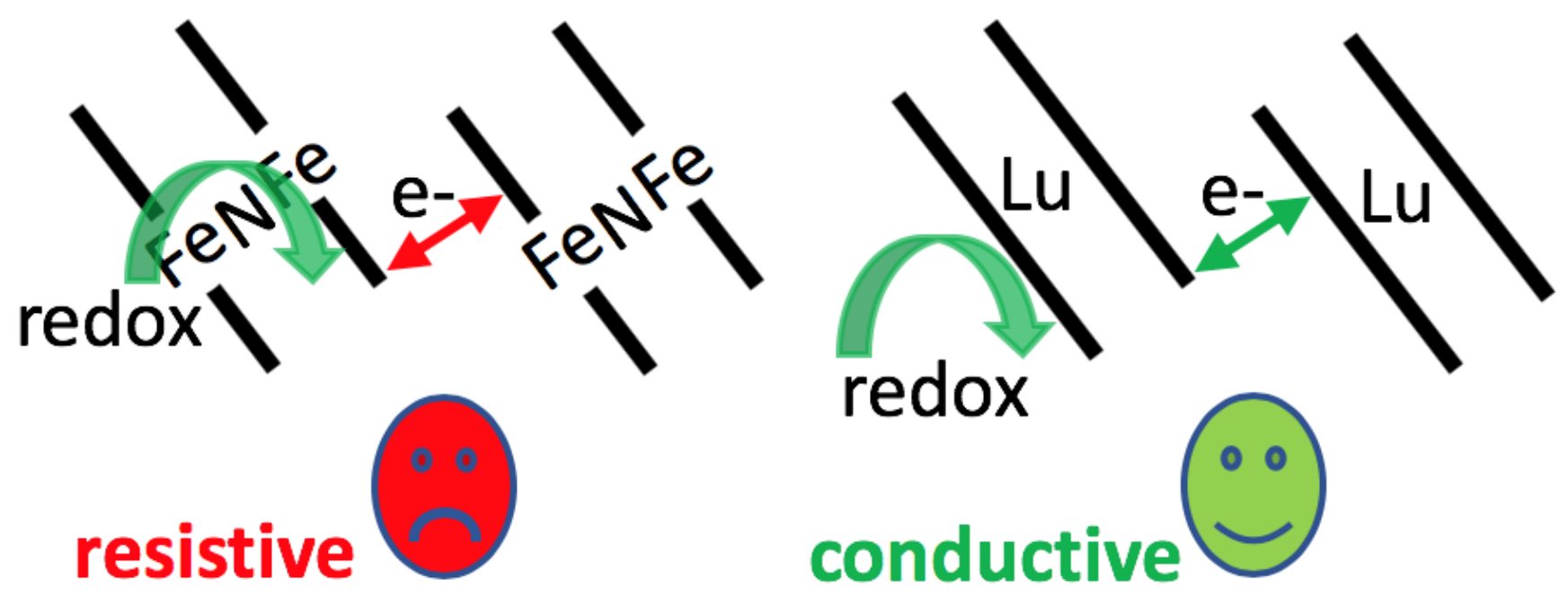




\title{
Alkylthio-tetrasubstituted $\mu$-Nitrido Diiron Phthalocyanines: Spectroe- lectrochemistry, Electrical Properties and Heterojunctions for Ammo- nia Sensing
}

\author{
Zeynel Şahin§, Rita Meunier-Prest ${ }^{\dagger}$, Fabienne Dumoulin§, Ümit Isci§*, Marcel Bouvet ${ }^{+*}$ \\ §Department of Chemistry, Gebze Technical University, 41400 Gebze - Kocaeli, Turkey \\ †Institut de Chimie Moléculaire de l'Université de Bourgogne (ICMUB), Université Bourgogne Franche-Comté, UMR CNRS \\ 6302, 9 avenue A. Savary, F-21078 Dijon, France
}

KEYWORDS molecular materials, phthalocyanine, conductometric transducer, heterojunction, gas sensor, ammonia

\begin{abstract}
Alkylthio-tetrasubstituted $\mu$-nitrido diiron phthalocyanines complexes are synthesized with $n$-butyl, iso-butyl, tert-butyl and $n$-hexadecyl alkyl moieties. For the first time, a spectroelectrochemical investigation of $\mu$-nitrido diiron phthalocyanines is achieved at all the redox steps. The complexes are stable in all their redox states, unlike their unsubstituted analogues. The interest of the present complexes is to prepare sensing devices by a solution processing method. Films are characterized by electronic absorption and Raman spectroscopies. Electrical measurements on resistors show the highly resistive behavior of these complexes, whatever the chain length. However, when combined with the lutetium bisphthalocyanine, an intrinsic semiconductor, these complexes form heterojunctions that exhibit a high sensitivity to ammonia, with a very good signal over noise ratio, at room temperature and in atmospheric conditions.
\end{abstract}

\section{INTRODUCTION}

Since the first unsubstituted $\mu$-nitrido diiron phthalocyanine reported in 1984, ${ }^{1}$ numerous $\mu$ nitrido dimetal phthalocyanine complexes were synthesized with different metals, e.g. Ru, Mn, and Re, ${ }^{2-4}$ and different substituted phthalocyanines, including heteroleptic complexes. ${ }^{5-10}$ The FeNFe fragment is quasi-linear, as determined by several crystal structures $^{11}$ and EXAFS studies, ${ }^{7}$ hence the two macrocycles are nearly parallel. $\mu$-Nitrido diiron macrocyclic complexes are widely used as catalysts, because of their capability to generate high-valent oxidizing active species. ${ }^{7,12}$

In these highly stable macrocyclic dimers, because of the bridging nitrogen atom, a bimetallic mixed valence system has to be considered. Thus, in the diiron complexes, the $\mathrm{Fe}^{\mathrm{III}}-\mathrm{N}=\mathrm{Fe}^{\mathrm{IV}}$ system, with one delocalized unpaired electron, was evidenced from Mössbauer and Electron Spin Resonance (ESR) analyses. ${ }^{13}$ The two iron atoms are equivalent and the $\mathrm{Fe}^{3.5}-\mathrm{N}=\mathrm{Fe}^{3.5}$ notation is generally adopted, even though the $\mathrm{Fe}^{\mathrm{IVNFe}}{ }^{\mathrm{IV}}$ form was also reported. ${ }^{14}$ In these complexes, the two macrocyclic rings are dianions $\mathrm{Pc}^{2-}$. They can be easily reduced and oxidized, but the first reduction and oxidation steps occur at the metal center, as depicted by spectroelectrochemistry. ${ }^{15}$ Even though three reduction steps and one oxidation step were observed for the unsubstituted diiron phthalocyanine complex by cyclic voltammetry, the spectroelectrochemical study dealt with only the first reduction and the first oxidation steps.

In the field of gas sensors, conductometic transducers are currently used, mainly with metal oxides operating at high temperatures. ${ }^{16}$ However, a need exists for gas sensors operating at room temperature. For such applications, molecular materials reveal to be good candidates. In the field of molecular material-based gas sensors, the interest for heterojunctions, using two materials instead of one in classical resistors, was clearly established in the last decade. ${ }^{17,18}$ Thus, we patented an original type of heterojunction combining a poor conducting material deposited on interdigitated electrodes with an intrinsic semiconductor, namely the lutetium bisphthalocyanine, LuPc$_{2} .{ }^{19-21}$ These heterojunctions exhibit higher performances than resistors prepared from the same molecular materials. In particular, their sensitivity and stability are better and they are capable to operate under a humid atmosphere. It was demonstrated that, in such a device, the energy barrier between the two molecular materials plays a key role in their transport and sensing properties. ${ }^{22}$

In this work, we report original $\mu$-nitrido diiron phthalocyanines bearing alkylthio substituents, -SR, with $\mathrm{R}=n$-butyl, iso-butyl, tert-butyl and $n$-hexadecyl, chosen to improve the solubility of these complexes. In addition to the chain length, the bulkiness of phthalocyanines' substituents is known to be likely to dramatically affect their properties, hence the three isomers of the butyl substituent were selected, in addition to two chain lengths. ${ }^{23}$ We studied the complexes by spectroelectrochemistry at all the redox steps. We prepared sublayers by solvent cast and we characterized the films by electronic absorption and Raman spectroscopies. Additionally, we report, for 
the first time on this type of compounds, the electrical properties of $\mu$-nitrido diiron phthalocyanine complexes, as resistors, and we engaged them as a component in molecular heterojunctions that we used as chemosensors to detect ammonia. Ammonia sensors are of interest for air quality monitoring in the fertilizer industry and in the food industry as well. A typical concentration range of interest is 10$100 \mathrm{ppm}^{24}$

\section{RESULTS AND DISCUSSION}

\section{Synthesis and characterization of diiron complexes}

$\mu$-Nitrido alkylthio tetrasubstituted diiron phthalocyanine complexes 3a-3d were synthesized from the 4-alkylthio-phthalonitriles 1a-1d, via the corresponding Fe(II) phthalocyanines $\mathbf{2 a - 2 d}$, according to a modified reported route (Scheme 1). ${ }^{15}$ 4-isobutylthio-phthalonitrile 1c, reported for the first time, was characterized by ${ }^{1} \mathrm{H}$ and ${ }^{13} \mathrm{C}$ NMR spectros-

Scheme 1. Preparation of $\mu$-nitrido complexes 3a-d. (a: $R=n$-butyl, $b: R=$ tert-butyl, $\mathrm{c}: \mathrm{R}=$ iso-butyl, $\mathrm{d}: \mathrm{R}=$ n-hexadecyl).

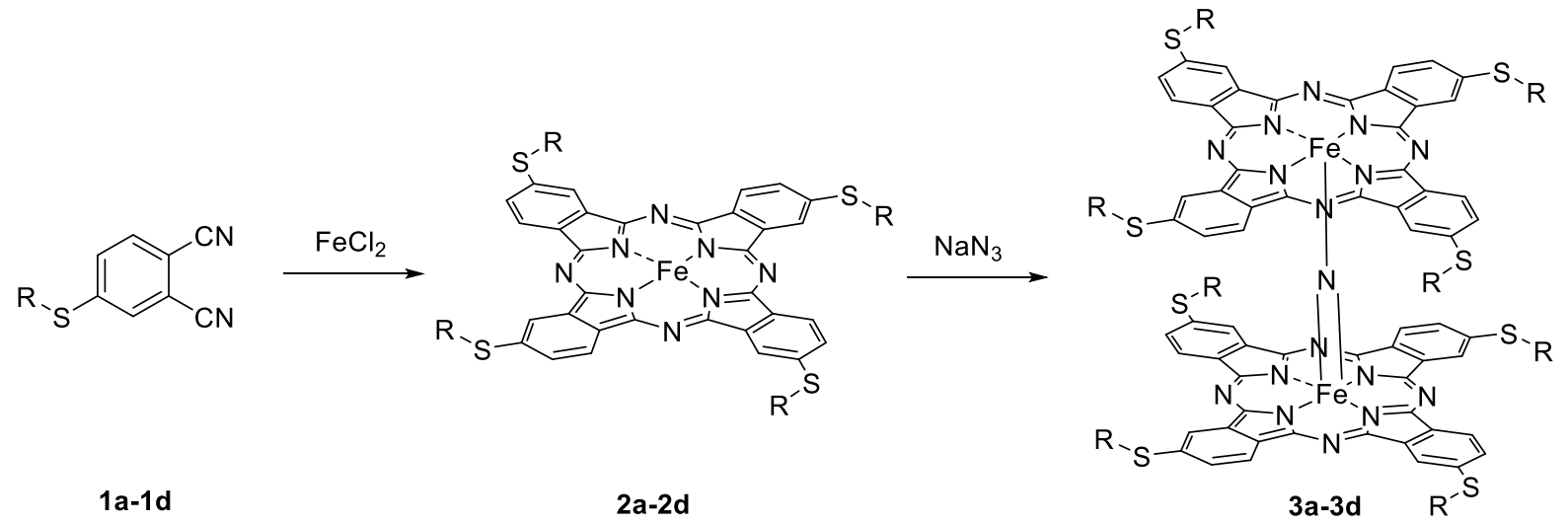

copies (Figure S1, S2) and by FT-IR spectroscopy (Figure S3). 2a, 2b and 2c were all prepared in ethylene glycol in $22-33 \%$ yield,

whereas 2d was prepared in solvent-free conditions and in similar yield (33\%), as it was not soluble enough neither in ethylene glycol nor in DMF which was also tried. The $\mu$-nitrido complexes could all be formed in refluxing xylene using a strong excess of sodium azide (caution: this hazardous reagent must be handled with care).

All the phthalocyanines were characterized by MALDI-TOF mass spectrometry (Figure S4-S11), by FT-IR spectroscopy (Figure 1, S12, S13), electron spin resonance (ESR) spectroscopy (Figure S14) and UVvis spectroscopy (Figure S15, S16), all evidencing the formation of the $\mu$-nitrido complexes. MALDI-TOF mass spectra confirmed the complete absence of starting monomeric phthalocyanines.

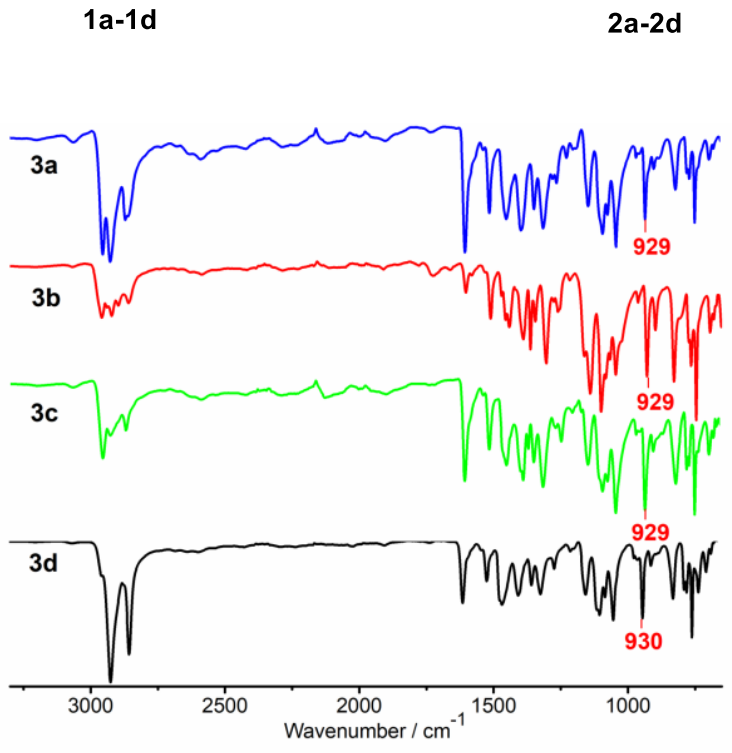

Figure 1. FT-IR spectra of $\mu$-nitrido diiron phthalocyanines $3 a(-), 3 b(-), 3 c(-)$ and $3 d(-)$

The strong anti-symmetric stretching vibration at 929-930 $\mathrm{cm}^{-1}$, characteristic of $\mathrm{Fe}-\mathrm{N}=\mathrm{Fe}$ bonds (ab- sent in the spectra of 2a-d) was observed for complexes 3a-3d in their FT-IR spectra. The ESR spectra of 3a-3d complexes (Figure S14) exhibited a typical axially symmetric signal with g-tensor values of 2.01 and 2.10 belonging to $S=1 / 2$ species and indicative of an extensive delocalization over the two iron ions, with an antiferromagnetic coupling between $\mathrm{Fe}^{\mathrm{III}}$ and $\mathrm{Fe}^{\mathrm{IV}}$. 1,7

The electronic UV-vis absorption spectra of $\mu$ nitrido complexes exhibit a Q-band around 648-660 $\mathrm{nm}$ (Figure S15) significantly hypochromically shifted compared to the Q-band of monomeric phthalocyanines 2a-d (Figure S16), which are in the range $697-718 \mathrm{~nm}$. This blue shift is well observable when the UV-vis spectra are superimposed (Figure 2) and results from the intramolecular interactions between the two phthalocyanines macrocycles, in accordance with previous reports. ${ }^{15}$ In each series, the lowest wavelength was observed for the tertbutyl derivatives. 
Electrochemical and spectroelectrochemical studies

The $\mu$-nitrido diiron complexes $\mathbf{3 a - 3 d}$ were studied by cyclic voltammetry on a Pt disk electrode. In DMF, complexes 3a-3c exhibit five monoelectronic redox

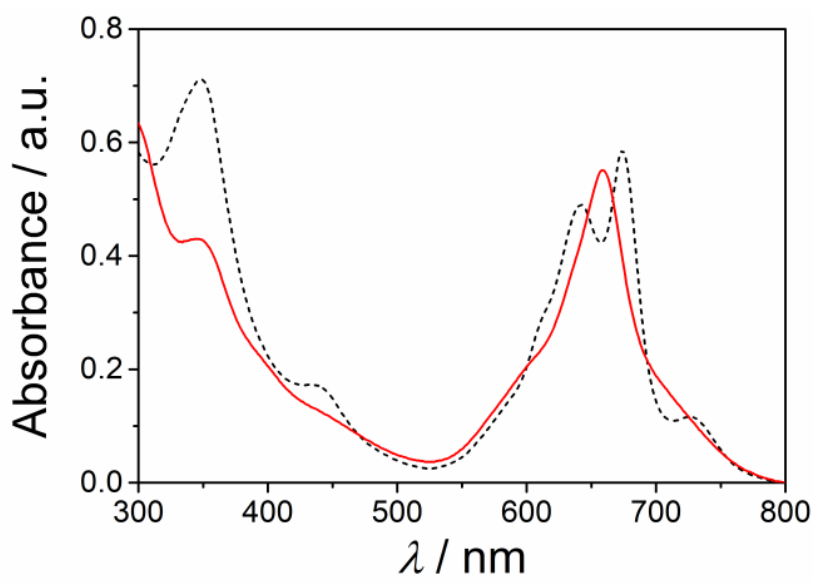

Figure 2. UV-vis spectra of monomeric iron phthalocyanine 2c $(--)$ and $\mu$-nitrido diiron phthalocyanine complexes 3c $(-)$ in DMF $(10 \mu \mathrm{M})$.

systems, namely three reduction and two oxidation steps (Figure 3). For all the compounds, they lie approximately at the same potential values. Thus, for 3c, the reduction systems appear at $E_{R e d 1}=-0.7$ $\mathrm{V}, E_{\text {Red } 2}=-1.0 \mathrm{~V}$ and $E_{R e d}=-1.3 \mathrm{~V}$ vs. SCE, and the oxidation systems at $E_{O \times 1}=+0.0 \mathrm{~V}$ and $E_{O \times 2}=+0.75 \mathrm{~V}$ vs. SCE (Figure 3).

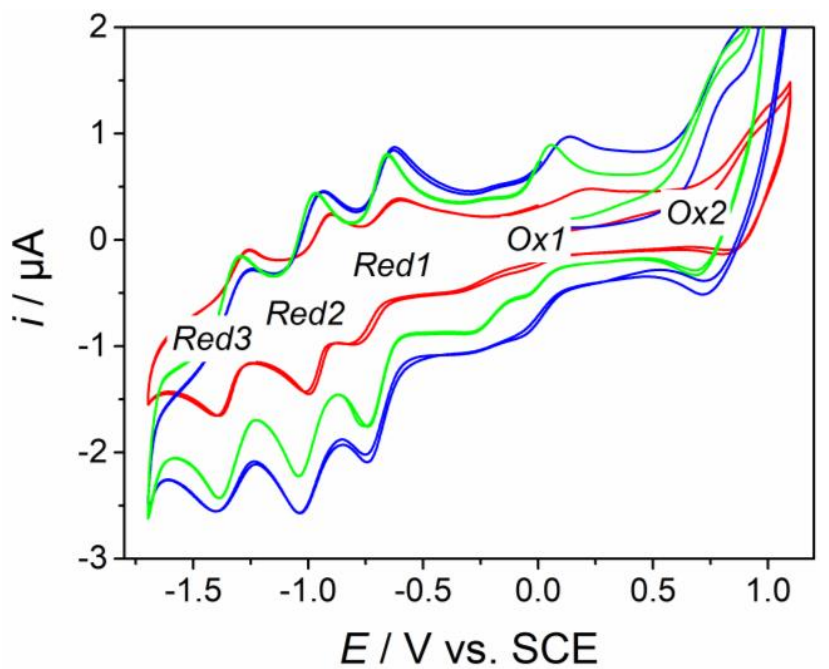

Figure 3. Cyclic voltammograms of $3 a(-), 3 b(-)$, $3 c(-)$ at $5 \times 10^{-4} \mathrm{M}$ in DMF + Bu $\mathrm{NPF}_{6} 0.1 \mathrm{M}$, on a Pt disk electrode (diameter $1.6 \mathrm{~mm}$ ) at a scan rate of $100 \mathrm{mV} \mathrm{s}^{-1}$.

The evolution of the reduction systems with variable scan rates, $v$, shows that the ratio $i_{p a} / i_{p c}$ is roughly equal to 1 and that the peak potentials do not vary with the scan rate, indicative of reversible processes. $\Delta E_{p}=E_{p a}-E_{p c}$, is somewhat larger than the theoretical value of $58 \mathrm{mV}$ for a reversible oneelectron transfer. Moreover, the intensity of all the peaks varies linearly with $v^{1 / 2}$ as expected in electrochemical reactions limited by the diffusion.

The first oxidation peak, at $E_{p a}^{O x 1}$ is associated with two reduction peaks, at $E_{p c 1}^{O x 1}$ and $E_{p c 2}^{O x 1}$. The relative intensity of the cathodic peaks varies with the scan rate. To understand the particular feature of this redox system, cyclic voltammograms were recorded on different potential windows (Figure S17). Thus, when stopping the reduction after $E_{p c 1}^{O x 1}$, the current associated with the anodic peak of $0 x 1$ decreased by a factor of two; it returned to its initial value when the potential was reversed after $E_{p c 2}^{O x 1}$. The existence of two cathodic peaks may be due to the coordination of a solvent molecule on the metal center. ${ }^{25}$ Indeed, formation or cleavage of metalligand bonds are particularly prevalent with coordination compounds. These reactions may influence the electrochemical mechanism. The methods for investigating the role of ligand exchange reactions by CV were systematized by Lexa et al. ${ }^{26}$

We examined the influence of addition of a coordinating solvent, such as pyridine, on the cyclic voltammograms. The results were analyzed using the square scheme theory in which all the redox states with and without coordinating solvent molecules were considered. ${ }^{27,28}$ The potentials of Red3 did not evolve when pyridine was added, whereas, Red1 and Red2 were shifted towards more negative values with slopes of -30 and $-60 \mathrm{mV} / \log \mathrm{c}_{\mathrm{py}}$. Concerning $0 x 1$, the peak potentials $E_{p a}^{O x 1}$ and $E_{p c 1}^{O x 1}$ did not move while $E_{p c 2}^{O x 1}$ was shifted towards more positive values with a slope of $30 \mathrm{mV} / \log c_{p y}$ and the ratio of the intensity of the two cathodic peaks varied with the pyridine concentration. The evolution of some peak potentials with the amount of pyridine is significant of ligand exchange reactions. In particular, for $0 \times 1$, it is in agreement with a greater affinity for axial ligands when the charge on the dimer increases. ${ }^{13,15}$ Such influence of the solvent has already been reported for $\mu$-nitrido iron porphyrin dimers. ${ }^{29}$ Their dependence is governed by the thermodynamics of the square scheme. In our case, except for $\operatorname{Red}_{2}$ that presents a slope corresponding to the coordination of one pyridine per molecule, exchanges of ligands involve less than one molecule per dimer probably due to competition with other ligands, in particular $\mathrm{H}_{2} \mathrm{O}$ and DMF. Furthermore, a potential shift of around $-30 \mathrm{mV}$ of all the redox systems was also observed when dried 3c was used (Figure S17), probably due to the coordination of a water molecule giving a more easily oxidized form. ${ }^{13,30}$ Because of aggregation phenomena in DMF, the complex $\mathbf{3 d}$ was studied in a $\mathrm{DMF} / \mathrm{CH}_{2} \mathrm{Cl}_{2}$ (9/1) mixture. Only the first oxidation 
and the first reduction systems were visible, at potentials $E_{\text {Red } 1}=-0.93 \mathrm{~V}$ and $E_{0 \times 1}=0.06 \mathrm{~V}$ vs. SCE.

To further understand the redox mechanism, especially to attribute the successive redox reactions to the phthalocyanine rings or to the metal centers, we carried out a complete spectroelectrochemical study on 3c (Figure 4). To date, the only spectroelectrochemical study on $\mu$-nitrido iron phtalocyanine dimer was reported by Bottomley et al. ${ }^{15}$ They demonstrated that the dimer is reduced in three successive steps and oxidized in one step. Spectra of the first electrogenerated cation and anion revealed complete retention of the bridging moiety whereas the other electron transfers resulted in the decomposition of the dimer giving the monomer. We performed successive electrolyses at fixed imposed potentials chosen after each redox system, first in reduction starting after $E_{p c}^{R e d 1}(-0.85 \mathrm{~V})$ to $E_{p c}^{R e d 3}(-$ $1.45 \mathrm{~V}$ ) (Figure 4 from a to $\mathrm{c}$ ), and back to $-0.3 \mathrm{~V}$ (Figure 4, from $d$ to f), then in oxidation (Figure 5). In this case, the imposed potential was chosen after the first redox system, $0 x 1$, back to $-0.5 \mathrm{~V}$, then after the second redox system, $0 x 2$, and back again to $0.5 \mathrm{~V}$ (Figure 5, from a to d). The UV-visible spectrum of 3c in DMF (Figure 2) presents a strong adsorption band at $650\left(\varepsilon 8.09 \times 10^{4}\right)$ and two shoulders at $598\left(\varepsilon 3.02 \times 10^{4}\right)$ and $692 \mathrm{~nm}\left(\varepsilon 2.66 \times 10^{4}\right)$. It is similar to that reported for the non-substituted $\mu$ nitrido iron phtalocyanine dimer, ${ }^{15}$ but the bands were redshifted by nearly $50 \mathrm{~nm}$ due to the presence of substituents and to the different solvent. Electrolysis at $-0.85 \mathrm{~V}$ induced only a very slight decrease of the absorbance of the $Q$ band, without modification of the general shape of the spectrum, showing that the first reduction step occurs at the metal center, as previously reported. ${ }^{13,15}$ The second electrolysis, at $-1.15 \mathrm{~V}$, lead to a decrease of the $\mathrm{Q}$ band, and an increase of a band that starts at 535 $\mathrm{nm}$ and finish at $540 \mathrm{~nm}$. This reduction step can again deal with the reduction of a metal center. Contrarily, the electrolysis at $-1.45 \mathrm{~V}$ lead to stronger modifications of the spectrum, with the almost disappearance of the band at $650 \mathrm{~nm}$, the high increase of the peak at $535 \mathrm{~nm}$ and the appearance of a new peak at $713 \mathrm{~nm}$. Clearly this step occurs on a phthalocyanine ring since absorption around 500 $\mathrm{nm}$ is typical of the spectra of metallophthalocyanine anion radical obtained after electron transfer on the macrocycle. ${ }^{31}$ But, when coming back to -1.1 $\mathrm{V}$, the spectrum does not evolve substantially, which indicates that the reoxidation occurs at first at the metal center. It can be noticed a small evolution of the spectrum between the last spectrum of Figure $4 \mathrm{c}$ and the first spectrum of Figure $4 \mathrm{~d}$, probably due to oxidation by oxygen, the cell being not perfectly airtight. During electrolysis at $-0.75 \mathrm{~V}$, the bands at
500 and $713 \mathrm{~nm}$ decrease and a band at $644 \mathrm{~nm}$ began to increase. Finally, the initial spectrum is fully recovered by electrolysis at $-0.3 \mathrm{~V}$ (Compare first spectrum of $4 \mathrm{a}$ and last spectrum of $4 \mathrm{f}$ ). The $\mu-$ nitrido diiron phthalocyanines are known to be very stable species due to the remarkable stability of the $\mathrm{Fe}-\mathrm{N}=\mathrm{Fe}$ bridge. ${ }^{32}$ It is important to note that the destruction of the dimer during the second and/or the third reduction steps would induce the formation of monomer and, therefore, the emergence of two bands at 642 and $674 \mathrm{~nm}$ (see spectrum of 2c in Figure 2). This is not the case, contrarily to what was observed with unsubstituted complexes. ${ }^{15}$ The $\mu$-nitrido diiron phthalocyanines bearing alkylthio substituents present a higher stability compared to the unsubtituted $\mu$-nitrido diiron phthalocyanines. Moreover, the latter report was performed in pyridine, a strong coordinating solvent, which may facilitate the momomerization of dimers.

In oxidation, the imposed potential was chosen after the first redox system, back to $-0.5 \mathrm{~V}$, then after the second redox system and back again to $-0.5 \mathrm{~V}$. The first oxidation induced a small red shift of the $Q$ band from 650 to $655 \mathrm{~nm}$ (Figure 5) showing that the electron transfer occurs on the metal as for the unsubstituted dimer. ${ }^{15}$ The spectrum recorded after electrolysis at $-0.5 \mathrm{~V}$ is fully superimposable with that before oxidation, attesting that the redox process is perfectly reversible. It occurs with complete retention of the bridge in agreement with what was previously reported. 15 During oxidation of the starting species at $+1 \mathrm{~V}$, the $\mathrm{Q}$ band was also shifted from 650 to $655 \mathrm{~nm}$ (Figure 5) and two shoulders appeared at 594 and $713 \mathrm{~nm}$. After electrolysis at $0.5 \mathrm{~V}$ the spectrum was different from that before electrolysis: the band at $650 \mathrm{~nm}$ remained visible but less important and a band at $670 \mathrm{~nm}$ appeared certainly due to partial destruction of the product during the second oxidation step. This induced the possible formation of the monomer characterized by the band at $670 \mathrm{~nm}$.

To get an overview of the electronic absorption modifications, the starting complex and the most reduced and oxidized states were superimposed (Figure 6). Additionally, all the electronic absorption data, including maximum wavelengths and shoulders, and the corresponding molar extinction coefficient $\varepsilon=\mathrm{Abs} / \mathrm{c} . \mathrm{l}$, where $\mathrm{c}$ and $\mathrm{l}$ and the molar concentration in mol L-1 and the length of the optical path in $\mathrm{cm}$, respectively, were compiled in Table S1.

All these data allow attributing all the redox states (Scheme 2). For clarity, coordinated solvent molecules have been omitted. It is worth noting that the redox steps are different when going from 0 to $1.85 \mathrm{~V}$ and when coming back to $0 \mathrm{~V}$. In the reduc- 
tive direction, $\mathbf{3 b}$ is first reduced in two redox reactions at the metal centers (Red1 and Red2), induc- ing only small modifications on the UV-vis spectra (Figure 4a,b).
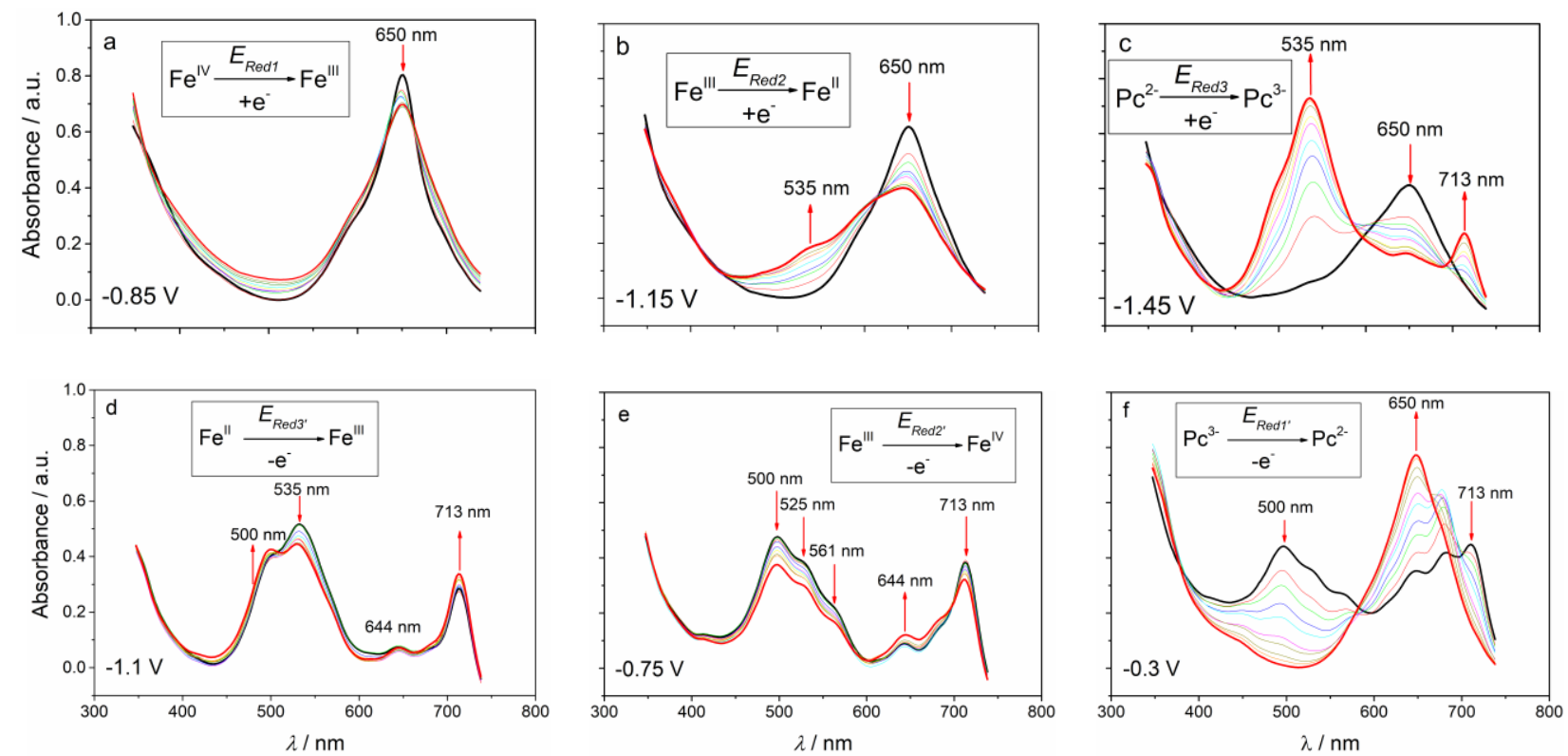

Figure 4. Successive spectroelectrochemical experiments performed on the reduction systems of dried $3 \mathrm{c} 10^{-4}$ $\mathrm{M}$ in $\mathrm{DMF}+\mathrm{Bu}_{4} \mathrm{NPF}_{6} 0.1 \mathrm{M}$ each during $960 \mathrm{~s}$. The imposed potentials were chosen after each redox system, first in reduction (a to $c$ ) then back to $-0.3 \mathrm{~V}$ ( $\mathrm{d}$ to $\mathrm{f}$ ).
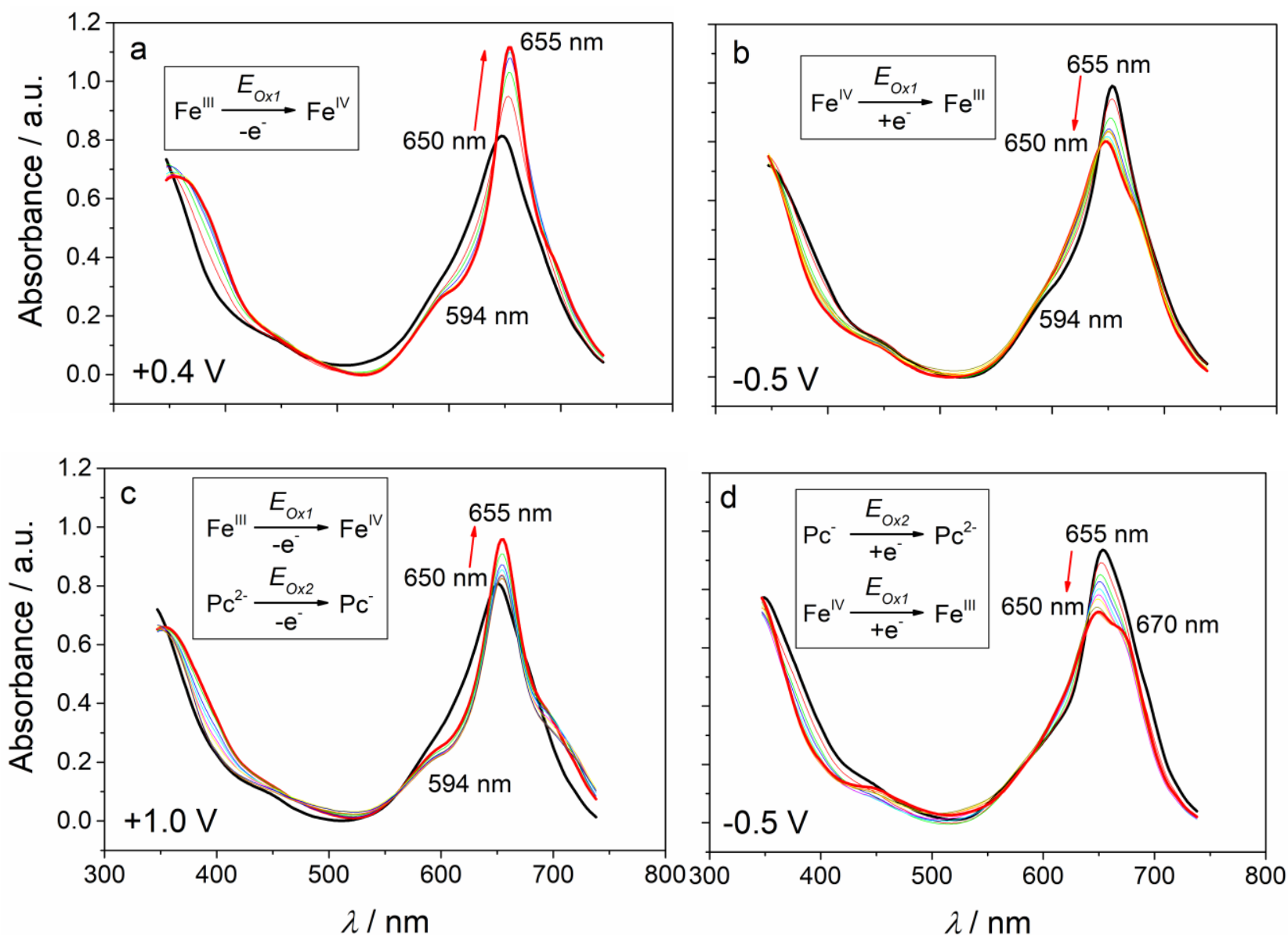
Figure 5. Successive spectroelectrochemical experiments performed on the oxidation systems of dried $3 \mathrm{c} 10^{-4}$ $\mathrm{M}$ in DMF + Bu $\mathrm{NPF}_{6} 0.1 \mathrm{M}$ each during $960 \mathrm{~s}$. First, the imposed potential was chosen after the first redox system (a), back to $-0.5 \mathrm{~V}(\mathrm{~b})$, then after the second redox system (c) and back again to $-0.5 \mathrm{~V}$ (d).

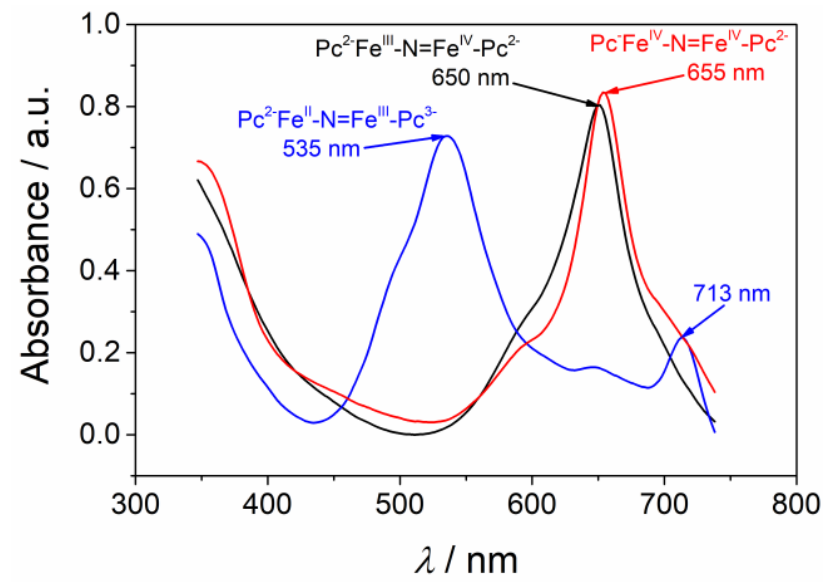

Figure 6. UV-vis electronic absorption spectra of 3c in DMF, in its neutral, triply reduced and doubly oxidized forms.

On the contrary, the third reduction occurs on the phthalocyanine ring, as shown by the huge modification of the electronic absorption spectrum. When coming back to $0 \mathrm{~V}$, the oxidation of $\left[\left(\mathrm{PcFe}^{2.5}\right)_{2} \mathrm{~N}\right]^{3-}$ takes place first at the metal centers (Red3' and Red2') causing little changes on the spectrum then on the phthalocyanine ring (Red1') to restore the initial product, 3c and leading great modifications of the spectrum. To confirm these results, cyclic voltammograms were recorded after each spectroelectrochemical experiment (Figure S18). After reduction at $-1.45 \mathrm{~V}$ (green curve), the voltammogram still presents 3 monoelectronic redox systems (Red1', Red2' and Red3'), but their potentials are shifted by around $+100 \mathrm{mV}$ compared to that of the initial voltammogram (red curve). The totally reduced species, $\left[\left(\mathrm{PcFe}^{2.5}\right)_{2} \mathrm{~N}\right]^{3-}$, involves different redox reactions as those observed for $\mathbf{3 c}$. This result corroborates the hypothesis of two different pathways depending on whether the initial product is $\mathbf{3 c}$ or the totally reduced species, $\left[\left(\mathrm{PcFe}^{2.5}\right)_{2} \mathrm{~N}\right]^{3-}$. After electrolysis at $-0.3 \mathrm{~V}, 3 \mathrm{c}$ is restored and the voltammogram once again becomes the same as that before spectroelectrochemistry (blue curve). When going from 0 to $+1 \mathrm{~V}, 3 \mathrm{c}$ is first oxidized at the metal center (Ox1), then on the phthalocyanine ring $(0 x 2)$. The same path is followed when coming back to $0 \mathrm{~V}$.

Scheme 2. Redox mechanism for 3c, as deduced from spectroelectrochemistry.

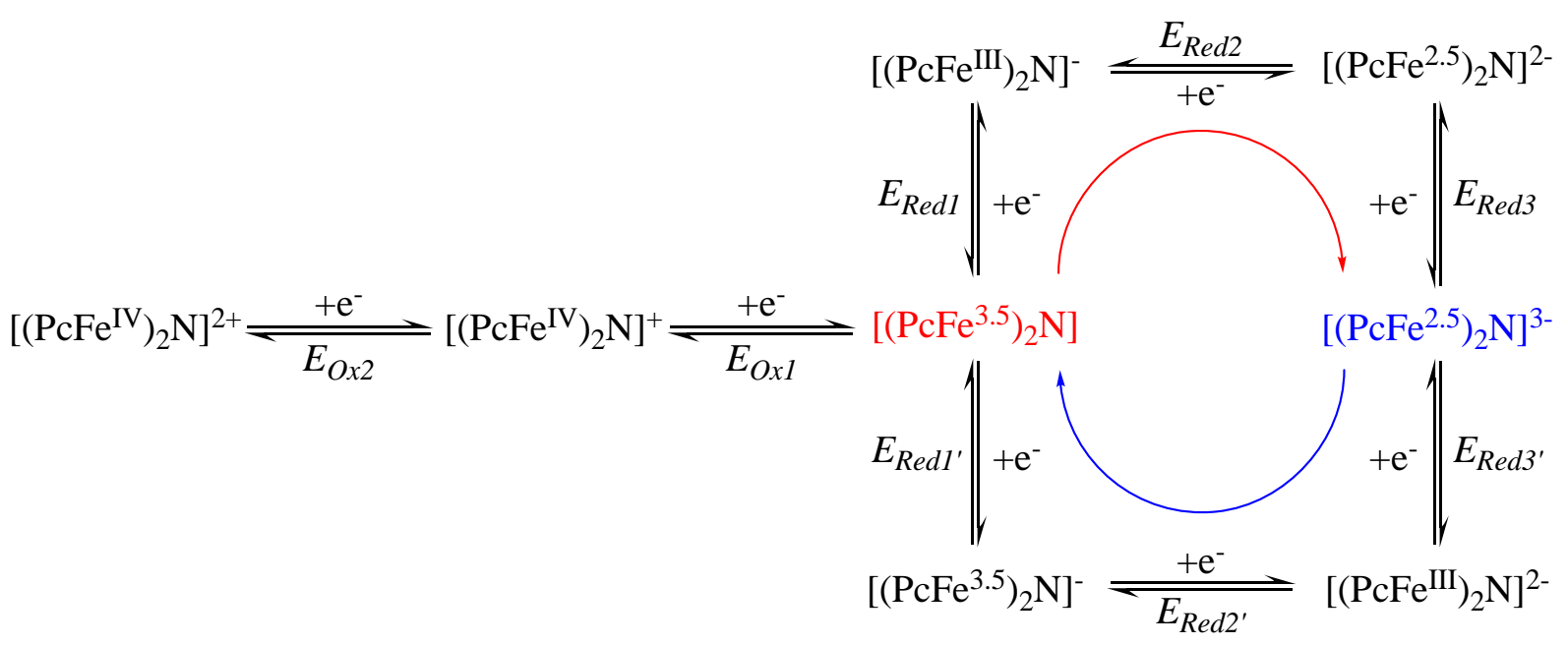

Electrochemical potentials were used to evaluate the energy values of the frontier orbitals, HOMOs and LUMOs. Generally, the onset potential (E $\mathrm{E}_{\text {ONSET }}$ ) defined as the potential at which the initial electron transfer from the HOMO, or to the LUMO, becomes visible on the cyclic voltammogram as a rise in anodic or cathodic current, respectively, is used..$^{33,34}$ The energy of HOMOs ( $\mathrm{E}_{\text {номо }}$ ) and LUMOs ( $\left.\mathrm{E}_{\mathrm{Lumo}}\right)$ was determined from the onset of their redox po- tentials determined in solution versus SCE, as reference electrode:

$$
\begin{aligned}
& E_{\text {Номо }}=-\left(E_{\text {onset } / S C E}^{\text {ox } 1}+4.4\right) \\
& E_{\text {LUMO }}=-\left(E_{\text {onset } / S C E}^{\text {red } 1}+4.4\right)
\end{aligned}
$$

Thus, $\mathrm{E}_{\text {номо }}$ and $\mathrm{E}_{\mathrm{Lumo}}$ of compounds 3a-3c lie very near from each other, at ca. -4.4 and $-3.8 \mathrm{eV}$, and those of $\mathbf{3 d}$ at -4.3 and -3.6 , respectively (Table 
1). This leads to an energy gap of ca. $0.6 \mathrm{eV}$, which is a very low value for a molecular material. However, the HOMO and LUMO deal with the metal centers and not macrocycles. As a consequence, in the solid state, the intrinsic density of charge carriers that results from intermolecular charge transfers and involves the oxidation and reduction states of neighboring molecules will be very small. ${ }^{35}$ On the contrary, the lutetium bisphthalocyanine, $\mathrm{LuPc}_{2}$, known as the first intrinsic molecular semiconductor $^{21}$ exhibits a very low energy gap, ca. $0.5 \mathrm{eV}$, related to redox states formed by intermolecular electron transfer at the macrocycle level.

Table 1. Eonset of first oxidation and reduction steps of compounds 3a-3d, as determined vs SCE, and $\mathbf{E}_{\text {номо }}$ and $E_{\text {Lumo }}$ deduced from Equation 1 and 2.

\begin{tabular}{|c|c|c|c|c|}
\hline & $\begin{array}{c}\text { EONSET,Ox1 } \\
\text { (V) }\end{array}$ & $\begin{array}{c}\text { EONSET,R1 } \\
(\mathrm{V})\end{array}$ & $\begin{array}{c}\text { Е }_{\text {HOMO }} \\
(\mathrm{eV})\end{array}$ & $\begin{array}{c}\text { ELUMO }_{\text {LUO }} \\
(\mathrm{eV})\end{array}$ \\
\hline $3 \mathbf{a}$ & -0.02 & -0.60 & -4.38 & -3.84 \\
\hline $3 b$ & +0.04 & -0.62 & -4.44 & -3.78 \\
\hline $3 c$ & -0.07 & -0.63 & -4.33 & -3.77 \\
\hline $3 d$ & -0.11 & -0.775 & -4.29 & -3.625 \\
\hline
\end{tabular}

Electronic absorption and Raman spectroscopies

Films of $\mathbf{3 a}$ and $\mathbf{3 d}$, the complexes having both linear chains of different lengths, were obtained by solvent cast, from $85 \mu \mathrm{L}$ for $\mathbf{3 a}$ and $40 \mu \mathrm{L}$ for $\mathbf{3 d}$ of $\mathrm{CHCl}_{3}$ solutions, at concentrations of $1 \mathrm{mg} \mathrm{mL}^{-1}$, equivalent to $5.9 \times 10^{-4}$ and $3.1 \times 10^{-4} \mathrm{M}$, for $3 \mathbf{a}$ and 3d, respectively, deposited dropwise on glass and on interdigitated electrodes (IDE). The depositions were carried out at room temperature, then the substrates were heated for 3 hours, at $60{ }^{\circ} \mathrm{C}$, in a closed desiccator, in order to fully evaporate the solvent and increase the homogeneity of the films. The electronic absorption spectra of films show Qbands, at 664 and $668 \mathrm{~nm}$ for 3a and 3d, respective- ly, with a small bathochromic shift compared to molecules in $\mathrm{CHCl}_{3}$ solutions, of 7 and $13 \mathrm{~nm}$, respectively, showing rather edge-to-edge intermolecular interactions in the solid state (J-type aggregates). ${ }^{36}$

From these films, we build heterojunctions, by vacuum evaporation of lutetium bisphthalocyanine, $\mathrm{LuPc}_{2}, 50 \mathrm{~nm}$ in thickness. Electronic absorption and Raman spectroscopies analysis was conducted on the heterojunctions and compared to these of each material deposited as films. The electronic absorption spectra of bilayers were the superimposition of the spectra of each material, as shown in Figure 7 for 3a, showing no significant charge transfer between the two layers. The spectra of $\mathbf{3 d} / \mathrm{LuPc}_{2}$ are shown in Figure S19. Even though the films of $\mu-$ nitrido diiron phthalocyanines are very thick (ca. $500 \mathrm{~nm}$ ), compared to the thickness of the $\mathrm{LuPc}_{2}$ top layer $(50 \mathrm{~nm})$, the Raman spectra of the bilayer devices, registered between 500 and $1800 \mathrm{~cm}^{-1}$, confirm the presence of both materials, as exemplified by the spectrum of $\mathbf{3 a} / \mathrm{LuPc}_{2}$, in particular, in the $1350-1700 \mathrm{~cm}^{-1}$ range (Figure 8 ).

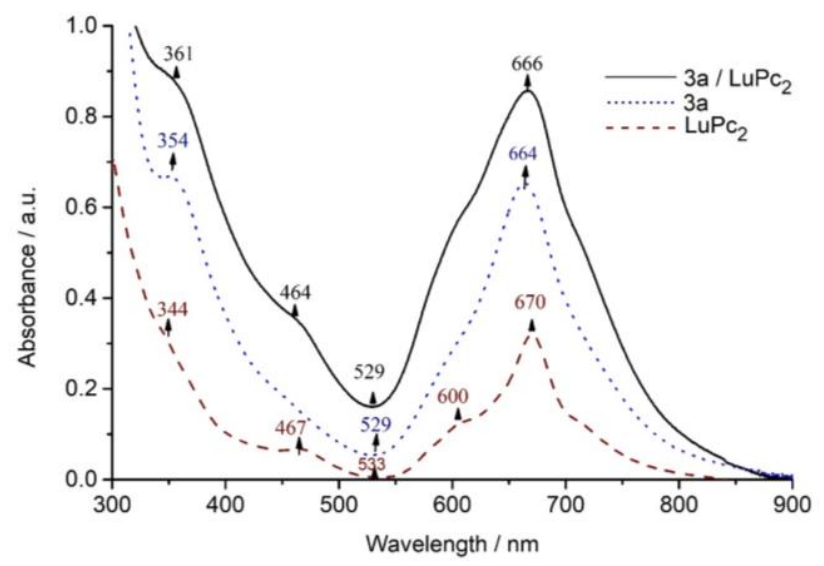

Figure 7. UV-vis electronic absorption spectra of a film of $3 \mathrm{a} / \mathrm{LuPc}_{2}$ on glass (black line), compared to those of 3a (dotted line) and LuPc 2 (dashed line) films. 

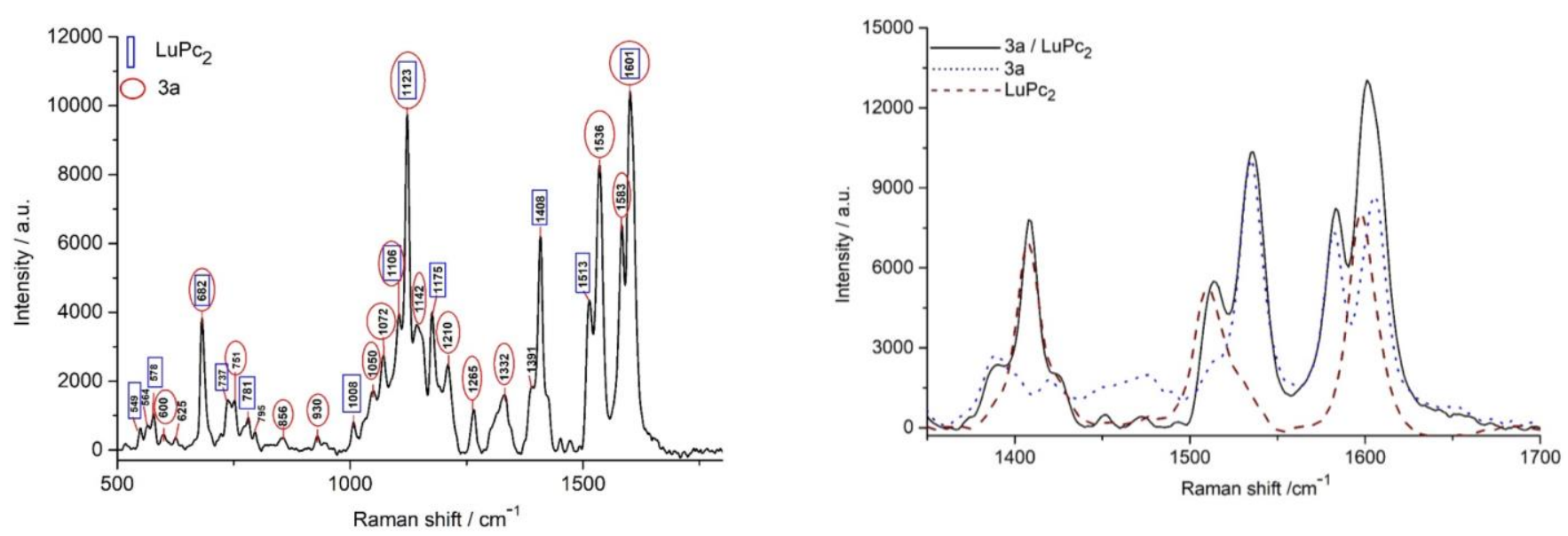

Figure 8. (Left) Raman spectra of a $3 a / L u P c_{2}$ device, with the peaks attributed to $3 a$ (encircled), to LuPc 2 (rectangle) and to both, and (right) a zoom of one Raman shift range of this device (black line) compared to these of 3a (dash dotted line) and to LuPc2 (dotted line) films.

The full Raman spectra of $\mathbf{3 a}, \mathbf{3 d}$ and $\mathrm{LuPc}_{2}$ are given as supplementary information (Figure S20, S21). The Raman spectrum of $\mathbf{3 a} / \mathrm{LuPc}_{2}$ shows peaks that can be attributed to the sublayer, namely the peaks at 1583, 1536 and $1123 \mathrm{~cm}^{-1}$ that correspond to three out of the four more intense peaks of 3a, but also the peaks at 1391, 1332, 1265, $1210,1142,856,751$ and $600 \mathrm{~cm}^{-1}$. The peaks at $1513,1408,1175,781,578$ and $549 \mathrm{~cm}^{-1}$ belong to $\mathrm{LuPc}_{2}$. In addition, four peaks are common to both materials, at 1601, 1123, 1106 and $682 \mathrm{~cm}^{-1}$. The strong peak of $\mathrm{LuPc}_{2}$, at $1598 \mathrm{~cm}^{-1}$ merged with the peak at $1606 \mathrm{~cm}^{-1}$, the most intense of $\mathbf{3 a}$, in the spectrum of the bilayer. The attribution of all these peaks, compiled in Table S2, was possible from Raman spectra of a series of phthalocyanines reported in litterature. ${ }^{37}$ In particular, the peaks in the range $500-700 \mathrm{~cm}^{-1}$ correspond to the phthalocyanine macrocycle breathing, and these at 1123 and $1175 \mathrm{~cm}^{-1}$ to $\mathrm{C}-\mathrm{H}$ bending. The peak at $1331 \mathrm{~cm}^{-1}$ corresponds to $\mathrm{C}=\mathrm{C}$ pyrole and benzene stretching and the one at $1408 \mathrm{~cm}^{-1}$ to isoindole stretching. The peak at $1513 \mathrm{~cm}^{-1}$ corresponds to the coupling of pyrrole and aza stretching. Finally, the peaks at 1583, 1596 and $1601 \mathrm{~cm}^{-1}$ are attributed to benzene stretching.

\section{Electrical and sensing properties}

Electrical measurements in ambient atmosphere and at room temperature of resistors made from $\mu$ nitrido diiron phthalocyanines $\mathbf{3 a}$ and $\mathbf{3 d}$ showed that they were highly resistive. At $+10 \mathrm{~V}$, the current was $3 \times 10^{-9} \mathrm{~A}$ for $\mathbf{3 a}$, but only $3 \times 10^{-10} \mathrm{~A}$ for $\mathbf{3 d}$, as a result of longer alkyl chains, paraffin wax being known as an insulating material. Thus, their conductivity was in the range $10^{-9}-10^{-10} \Omega^{-1} \mathrm{~cm}^{-1}$, values identical to these of monomeric phthalocyanines. Despite this very low conductivity, it was possible to engage these materials as sub-layers in heterojunctions, by vacuum evaporation of lutetium bisphthalocyanine, $\mathrm{LuPc}_{2}, 50 \mathrm{~nm}$ in thickness, on films of $\mathbf{3 a}$ and $\mathbf{3 d} . \mathrm{LuPc}_{2}$ is an intrinsic molecular semiconductor already reported by the authors as a key material to build molecular heterojunctions with different materials and geometries. ${ }^{20,38,39}$

Because of the very near molecular structure of the four $\mu$-nitrido complexes, we carried out the electrical and sensing measurements only on two compounds, namely $\mathbf{3 a}$ and $\mathbf{3 d}$. A key point to keep the advantage of the heterojunction configuration, compared to a classical resistor made from $\mathrm{LuPc}_{2}$, is to get a sublayer covering all the surface of the substrate without any hole. This is the reason why we chose compounds $\mathbf{3 a}$ and $\mathbf{3 d}$, which are more filmogenic than the others, as depicted from the homogeneity of the films.

The I-V characteristics obtained with the 3a/ $\mathrm{LuPc}_{2}$ and $\mathbf{3 d} / \mathrm{LuPc}_{2}$ heterojunctions are symmetrical but not linear (Figure 9), contrarily to what is observed for $\mu$-nitrido diiron complexes resistors and for a $\mathrm{LuPc}_{2}$ resistor, in the same potential range. For heterojunctions, a plateau exists at low voltages, but above a given potential the I-V curve is linear. Thus, a threshold voltage was determined by extrapolation of the linear part, with values of 1.9 and $4.1 \mathrm{~V}$, for $3 \mathrm{a} / \mathrm{LuPc}_{2}$ and $\mathbf{3 d} / \mathrm{LuPc}_{2}$, respectively. This shows that an energy barrier exists between the molecular materials or between the electrodes and the sublayer. ${ }^{20}$ As a result, the non-linearity is greater with 3d, with a smaller current, ca. $0.4 \mu \mathrm{A}$ at $10 \mathrm{~V}$, against $8.0 \mu \mathrm{A}$ at the same bias voltage with $3 a$.

Under $\mathrm{NH}_{3}$, the $\mathbf{3 a} / \mathrm{LuPc}_{2}$ (Figure 9b) and 3d/LuPc2 (Figure 9d) heterojunctions exhibit a current decrease, as expected for a p-type device. 
This is in accordance with heterojunctions prepared from a p-type sublayer covered by $\mathrm{LuPc}_{2}{ }^{20}$ This reveals that compounds $\mathbf{3 a}$ and $\mathbf{3 d}$ are capable of transporting majority positive charge carrier, even though their density remains very low, as demonstrated by the above mentioned resistors.

Measurements were carried out under controlled relative humidity (RH). The response to $\mathrm{NH}_{3}$ depends on its concentration. For example, for the $3 \mathrm{a} / \mathrm{LuPc}_{2}$ heterojunction, the response to $30 \mathrm{ppm}$ $\mathrm{NH}_{3}$, given by $\mathrm{I}_{\text {on }}-\mathrm{I}_{\text {off }}$, was $-4 \times 10^{-3} \mu \mathrm{A}$, which corresponds to a relative response, $\mathrm{RR}$, defined as $\mathrm{RR}=$ ( $\left.\mathrm{I}_{\text {on }}-\mathrm{I}_{\text {off }}\right) / \mathrm{I}_{\text {off }}$, of $-11 \%$. This value is lower than the one obtained with a n-type heterojunction combining a perfluoro-phthalocyanine as a sub-layer and $\mathrm{LuPc}_{2}$, about $+45 \%$ at $30 \mathrm{ppm},{ }^{22}$ but comparable with the RR of a p-PTFANI/LuPc 2 heterojunction. ${ }^{38}$ The RR of the present heterojunction is higher than the one obtained with a n- $\mathrm{WO}_{3} / \mathrm{LuPc}_{2}$ heterojunction, ${ }^{40}$ and higher than with other p-type heterojunctions, e.g. $-2 \%$ for a $\mathrm{Cu}\left(\right.$ tert- $\left.\mathrm{Bu}_{4} \mathrm{Pc}\right) / \mathrm{LuPc}_{2}$ heterojunction. ${ }^{41}$ For the $\mathbf{3 d} / \mathrm{LuPc}_{2}$ heterojunction, measurements were carried out at a bias of $5 \mathrm{~V}$, to compensate the higher resistivity of the device. It exhibits a lower sensitivity, with a response to 30
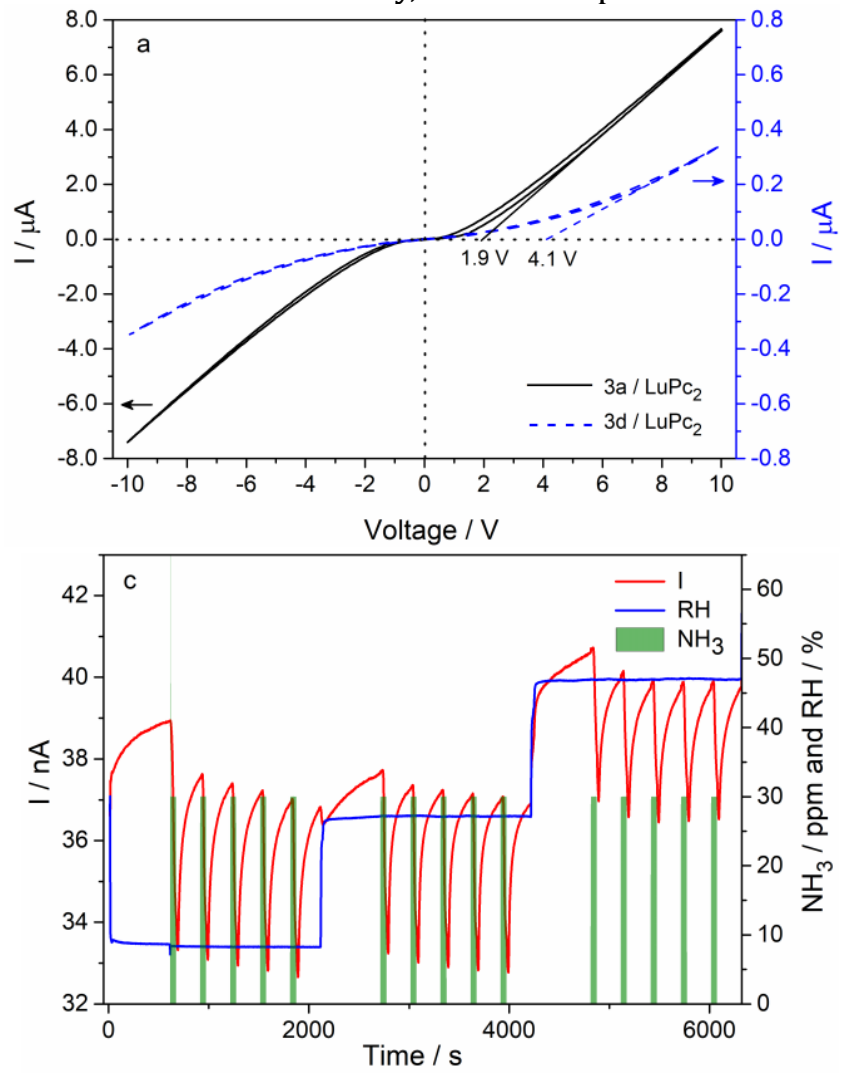

ppm and $10 \mathrm{ppm} \mathrm{NH}_{3}$ of $-3 \times 10^{-3} \mu \mathrm{A}$ and $-1.4 \times 10^{-3}$ $\mu \mathrm{A}$, respectively, which corresponds to RR values of $-4 \%$ and $-2.3 \%$, respectively. We studied the response to $\mathrm{NH}_{3}$ at different $\mathrm{RH}$ values (Figure 9c). The baseline current was unchanged between 10 and $30 \% \mathrm{RH}$, increased slightly between 30 and $50 \% \mathrm{RH}$, but increased dramatically when going to $70 \%$ RH. This means that this ammonia sensor could operate in atmospheres with a moderate $\mathrm{RH}$ value.

It is worth noting that the effect of the humidity on the response of gas sensors is rarely studied. Additionally, even though inorganic material based conductometric sensors can exhibit higher sensitivity, they operate generally at high temperature, ${ }^{42}$ contrarily to the present devices. So, the performances of the present devices, prepared partially by solution processing are comparable to these of previously reported heterojunctions. This solution processing step is an important point towards a simple preparation of such sensors, keeping a good sensitivity, even at various relative humidity values.
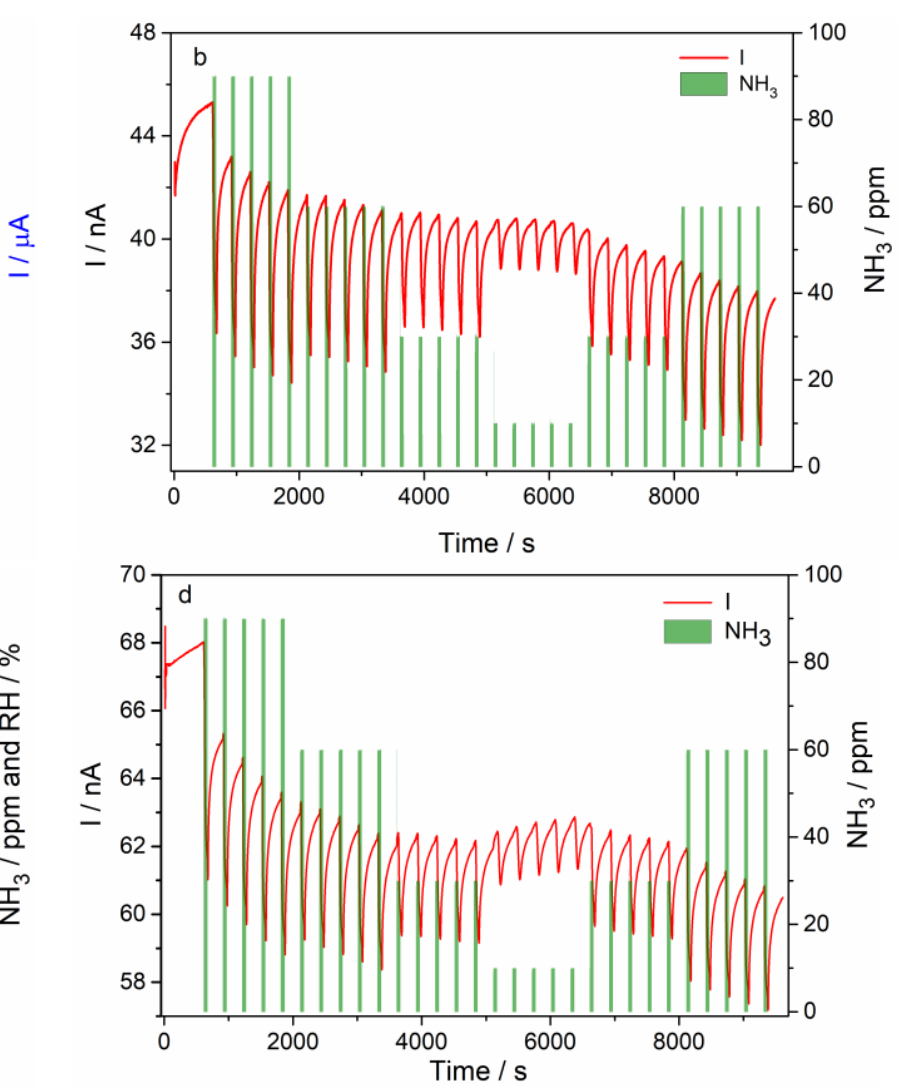

Figure 9. a) Current-voltage characteristics of $3 a / L u P c_{2}$ and $3 d / L u P c_{2}$ heterojunctions; the value of the threshold voltage is given for the two devices; b) response of a $3 \mathrm{a} / \mathrm{LuPc}_{2}$ heterojunction to ammonia in the

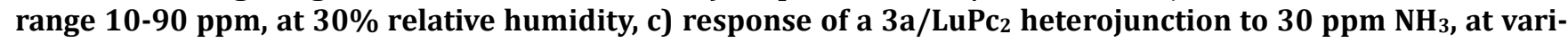
ous relative humidity values, both during exposure/recovery cycles (1 min/4 min), at RT, with a bias of $1 \mathrm{~V}$. and d) response of a $3 \mathrm{~d} / \mathrm{LuPc}_{2}$ heterojunction to ammonia in the range $10-90 \mathrm{ppm}$, at $30 \%$ relative humidity, with a bias of $5 \mathrm{~V}$. 


\section{CONCLUSION}

In this paper, we reported for the first time the synthesis of alkylthio tetrasubstituted $\mu$-nitrido diiron phthalocyanines. Starting from 4alkylthiophthalo-nitriles, these complexes were obtained by reaction of the corresponding iron monophthalocyanine complexes with sodium azide, in good yields. Their structures were confirmed by mass spectroscopy, FT-IR, UV-vis and ESR spectroscopies. Cyclic voltammetry in DMF showed the existence of two oxidation and three reduction processes. Spectroelectrochemistry showed that all the redox states are stable and that the first oxidation and the two first reduction steps occur at the metal center. However, the reoxidation from the 3 electron reduced species did not occur in the same pathway than the reduction.

Films prepared by solvent cast revealed to be highly resistive, showing that intermolecular charge transfer was not easy in the solid state, which occurs via the phthalocyanine macrocycles and not via the metal centers. However, deposition of the unsubstituted lutetium bisphthalocyanine complex by evaporation under secondary vacuum on films of $\mu$ nitrido diiron complexes, allowed us obtaining heterojunctions. The heterojunctions exhibited a positive response to ammonia, indicating that $\mu$-nitrido diiron complexes are p-type materials. The response to ammonia is only slightly sensitive to relative humidity changes in the range $10-50 \% \mathrm{RH}$.

\section{EXPERIMENTAL SECTION}

\section{Materials and methods}

4-Nitrophthalonitrile, ${ }^{43} \quad$ 4- $n$-butylthiophthalonitrile 1a, ${ }^{44}$ 4-tert-butylthio-phthalonitrile $\mathbf{1 b}{ }^{7,45,46}$ 4-hexadecylthiophthalonitrile $\mathbf{1 d}^{47}$ and the lutetium bisphthalocyanine ${ }^{48}$ were synthesized according to published procedures. Xylene was distilled from di-phosphorus pentoxide. All other reagents and solvents were purchased as reagent grade from Aldrich, Fluka or Merck and used without further purification.

FT-IR spectra were recorded between 4000 and $650 \mathrm{~cm}^{-1}$ using a PerkinElmer Spectrum 100 FT-IR spectrometer. Mass spectra were measured on a MALDI (matrix assisted laser desorption ionization) BRUKER Microflex LT (Bremen, Germany) using 1,8,9-anthracenetriol or 2,5-dihydroxybenzoic acid as the matrix. UV-visible electronic absorption spectra were recorded on a Shimadzu 2001 UV spectrophotometer. Raman spectroscopy was conducted employing a Renishaw inVia Raman microscope with a $473 \mathrm{~nm}$ laser. ESR spectra were recorded at $77 \mathrm{~K}$ on a Bruker ESP 300E spectrometer, using a standard rectangular (TE102) ESR cavity (Bruker
ER4102ST). Microwave power of $1.6 \mathrm{~mW}$ and modulation amplitude $1 \mathrm{G}$ were used.

Electrochemical studies.

All electrochemical experiments were performed with a PGSTAT302 N (Metrohm) potentiostat connected to a PC and the data collected were analyzed using the Nova ${ }^{\circledR} 2.1$ Software. Cyclic voltammetry (CV) of 3a-3c $5 \times 10^{-4} \mathrm{M}$ in DMF + $\mathrm{Bu}_{4} \mathrm{NPF}_{6} 0.1 \mathrm{M}$ was carried out by means of a three-electrode configuration consisting of the Pt disk $(1.6 \mathrm{~mm}$ in diameter, Bioanalytical Systems) as working electrode, a platinum wire as counter-electrode and a saturated calomel electrode (SCE) as reference separated from the solution by a glass chamber with a porous vycor tip filled up with a saturated solution of $\mathrm{Bu}_{4} \mathrm{NPF}_{6}$ in DMF. Potentials were reported versus SCE.

The working Pt disk electrode was soaked for 10 min in $\mathrm{KOH}(2 \mathrm{M})$, polished with $0.1 \mu \mathrm{m}$ alumina, etched for $10 \mathrm{~min}$ in concentrated sulfuric acid (2 $\mathrm{M})$ and sonicated $10 \mathrm{~min}$ in water, and then in absolute ethyl alcohol.

The solutions were deoxygenated for 10 min with argon, and a positive overpressure of argon was maintained above the electrolyte during the entire measurement performed at room temperature.

\section{Spectroelectrochemical studies.}

The in situ spectroelectrochemical experiments were performed on $3 c 10^{-4} \mathrm{M}$ in DMF + $\mathrm{Bu}_{4} \mathrm{NPF}_{6} 0.1$ $\mathrm{M}$ with a BioLogic cell having an optical path of 1 $\mathrm{mm}$. The working electrode was a gold grid, the reference electrode an SCE and the counter electrode a Pt wire. The spectroelectrochemical experiments were carried out with a PGSTAT302 N (Metrohm) potentiostat. The spectra were recorded every 3.2 seconds by a UV-visible diode array spectrometer (KINSPEC II/MMS-16 VIS, BIOLOGIC) running in the kinetic mode with external trigger. The $150 \mathrm{~W}$ Xe lamp and the spectrometer were connected to the cell by optical fibers.

\section{Device and electrical measurements.}

Electrical measurements were carried out with Indium Tin Oxide (ITO) interdigitated electrodes (IDE) separated by $75 \mu \mathrm{m}$ lithographied on a $1 \times 1$ $\mathrm{cm}^{2}$ glass substrate. Films of $\mathrm{LuPc}_{2}, 50 \mathrm{~nm}$ in thickness, were prepared by sublimation under secondary vacuum (ca. $10^{-6} \mathrm{mbar}$ ) in a UNIVEX 250 thermal evaporator (Oerlikon, Germany), at a rate of 1 A.. $\mathrm{s}^{-1}$. The other phthalocyanines were deposited by solvent cast technique from solutions in an organic solvent as described in the Results and Discussion section. Ammonia gas, 985 and 98 ppm in synthetic air, and synthetic air were used from standard gas cylinders, purchased from Air Liquide, France. Ammonia 
was diluted with dry synthetic air using mass flow controllers (total flow: 0.5 to $0.55 \mathrm{NL} \cdot \mathrm{min}^{-1}$ depending on ammonia concentration) in order to reach stable, controlled and adjustable ammonia concentrations from 1 to $90 \mathrm{ppm}$ and the volume of the test chamber was $8 \mathrm{~cm}^{3}$. The experimental setup used for electrical measurements and gas exposure was similar to the ones described in a previous work..$^{49}$ One dry line was used to control the flow of ammonia and another one to control the relative humidity by means of a water column and a humidity sensor (HMT-100, Vaisala, Finland). Gas sensing experiments were carried out in a dynamic way, by alternating 4 min-long rest periods and 1 min-long exposure periods. All experiments were carried out at a working temperature in the $18-22^{\circ} \mathrm{C}$ range.

\section{Syntheses.}

4-iso-butylthio-phthalonitrile (1c). A mixture of 4-nitrophthalonitrile (5.53 g, $31.9 \mathrm{mmol})$ and $\mathrm{K}_{2} \mathrm{CO}_{3}$ ( $44 \mathrm{~g}, 319 \mathrm{mmol}$ ) was stirred in DMF $(80 \mathrm{~mL})$ at room temperature for $10 \mathrm{~min}$. Then 2-methyl-1propanethiol $(4.10 \mathrm{~mL}, 38.3 \mathrm{mmol})$ was added, and the mixture was stirred at $50{ }^{\circ} \mathrm{C}$ for two days. Reaction mixture was cooled down to room temperature and poured into water. The resulting precipitate was filtered and washed several times with water. The residue was dissolved with dichloromethane and dried on sodium sulphate. Dichloromethane was evaporated, and the crude product purified on silica gel column chromatography using a mixture of dichloromethane and hexane (1/1). Yield: $87 \%$ (6 g). mp $85{ }^{\circ}$ C. FT-IR $\left(v, \mathrm{~cm}^{-1}\right)$ : 3091, 3062, 3024, 2963, 2925, 2223, 1586, 1541, 1466, 1390, 1370, $1279,1214,1130,1068,849,763 .{ }^{1} \mathrm{H}$ NMR $(500$ $\left.\mathrm{MHz}_{\mathrm{CDCl}}, \delta, \mathrm{ppm}\right): 1.07-1.09(\mathrm{~d}, 6 \mathrm{H}), 1.91-1.98$ (m, 1H), 2.88-2.90 (d, 2H), 7.48-7.50 (d, 1H), $7.55(\mathrm{~s}$, 1H), 7.62-7.63 (d, $1 \mathrm{H}) .{ }^{13} \mathrm{C}$ NMR $\left(125 \mathrm{MHz}, \mathrm{CDCl}_{3}, \delta\right.$, ppm): 22.14, 27.98, 40.70, 110.66, 115.32, 115.70, $116.27,130.05,130.16,133.24,147.87$.

\section{2,9(10),16(17),23(24)-Tetrakis(n-}

butylthio)phthalo-cyaninatoiron(II) (2a). Phthalonitrile $1 \mathrm{a}(1.0 \mathrm{~g}$, $4.62 \mathrm{mmol})$ and $\mathrm{FeCl}_{2}(313 \mathrm{mg}$, $2.48 \mathrm{mmol}$ ) were heated overnight at $140^{\circ} \mathrm{C}$ in ethylene glycol $(5 \mathrm{~mL})$ under argon. Reaction mixture was cooled and poured into a 1:1 water-ethanol mixture. The resulting precipitate was filtered off and washed several times with water-ethanol mixture. The residue was dissolved in dichloromethane and dried over sodium sulphate then concentrated. The crude product was purified on silica gel column chromatography using a mixture of dichloromethane and ethanol of increasing polarity (100:1 to 25:1). Yield: $33 \%$ (355 mg). MALDI-TOF-MS (matrix DIT) $\mathrm{m} / \mathrm{z}$ : $920.153[\mathrm{M}]^{+}$; calcd for $\mathrm{C}_{48} \mathrm{H}_{48} \mathrm{FeN}_{8} \mathrm{~S}_{4}$ : 920.223 . FTIR $\left(v, \mathrm{~cm}^{-1}\right): 2957,2926,2868,1599,1493,1448$,
1382, 1322, 1140, 1067, 1035, 955, 914, 893, 815, 761, 743, 688. UV-vis $\left(\mathrm{CHCl}_{3}\right): \lambda_{\max }(\log \varepsilon)=718$ (4.6), 602 (3.9), 355 (4.5) nm.

2,9(10),16(17),23(24)-Tetrakis(tert-butylthio)phthalocyaninatoiron(II) (2b). Phthalonitrile 1b $(1.0 \mathrm{~g}, 4.62 \mathrm{mmol})$ and $\mathrm{FeCl}_{2}(239 \mathrm{mg}, 2.31 \mathrm{mmol})$ was heated at $150^{\circ} \mathrm{C}$ in ethylene glycol $(5 \mathrm{~mL})$ under argon atmosphere overnight. Reaction mixture was cooled and poured into a mixture of water-ethanol $(1 / 1)$. The resulting precipitate was filtered and washed several times by the same mixture of ethanol-water (1/1). The residue was dissolved with dichloromethane and dried sodium sulphate. Dichloromethane was removed and the crude product was purified by column chromotography on silica gel using a mixture of dichloromethane and ethanol, with an increasing polarity, starting from 100:1 to 25:1 ratio. Yield: $26 \%$ (275 mg). MALDIMS (matrix DIT) $\mathrm{m} / \mathrm{z}$ : 920.858 [M]+; calcd for $\mathrm{C}_{48} \mathrm{H}_{48} \mathrm{FeN}_{8} \mathrm{~S}_{4}$ : 920.223. FT-IR ( $\left.\mathrm{v}, \mathrm{cm}^{-1}\right): 2959,2896$, $2860,1601,1511,1441,1389,1362,1303,1215$, 1161, 1139, 1081, 1044, 962, 926, 896, 828, 814, 764, 746, 692. UV-vis $\left(\mathrm{CHCl}_{3}\right): \lambda \max (\log \varepsilon)$ 697(4.8), 602 (4.1), 360 (4.7) nm.

\section{2,9(10),16(17),23(24)-Tetrakis(iso-butylthio)-} phthalocyaninatoiron(II) (2c). Phthalonitrile 1c (1.07 g, $4.94 \mathrm{mmol})$ and $\mathrm{FeCl}_{2}(313 \mathrm{mg}, 2.48 \mathrm{mmol})$ was heated overnight at $140^{\circ} \mathrm{C}$ in ethylene glycol (5 $\mathrm{mL}$ ) under argon. The cooled reaction mixture was poured into a mixture of water-ethanol (1/1). The resulting precipatate was filtered and washed several times with the same mixture of ethanolwater (1/1). The residue was dissolved in dichloromethane and dried over sodium sulphate then concentrated. The crude product was purified on silica gel column chromatography using a mixture of dichloromethane and ethanol of increasing polarity, starting from 100:1 to 25:1 ratio. Yield: $22 \%$ (255 mg). MALDI-MS (matrix DIT) $\mathrm{m} / \mathrm{z}$ : $920.264[\mathrm{M}]^{+}$; calcd for $\mathrm{C}_{48} \mathrm{H}_{48} \mathrm{FeN}_{8} \mathrm{~S}_{4}$ : 920.223 . FT-IR $\left(v, \mathrm{~cm}^{-1}\right): 2954,2926,2868,1599,1494$, $1447,1382,1322,1260,1168,1140,1067,1036$, 955, 914, 893, 814, 762, 743, 689. UV-vis $\left(\mathrm{CHCl}_{3}\right): \lambda$ $\max (\log \varepsilon)$ 712(4.8), 602 (4.0), 360 (4.7) nm.

2,9(10),16(17),23(24)-Tetrakis(hexadecylthio)phthalocyaninatoiron(II) (2d). A mixture of finely ground phthalonitrile $\mathbf{1 d}(1.295 \mathrm{~g}, 3.37 \mathrm{mmol})$ and $\mathrm{FeCl}_{2}$ (234 mg, $1.85 \mathrm{mmol}$ ) was heated overnight at $150{ }^{\circ} \mathrm{C}$ under argon. The cooled reaction mixture was dissolved in dichloromethane and filtrated to remove insoluble metal salt and impurities. Dichloromethane was removed and the crude product was purified on silica gel column chromotography using a mixture of dichloromethane and ethanol, with an increasing polarity, starting from 100:1 to 25:1 ratio. Yield: 33 
\% (450 mg). MALDI-TOF-MS (matrix DIT) $\mathrm{m} / \mathrm{z}$ : $1593,491[\mathrm{M}]^{+}$; calcd for $\mathrm{C}_{96} \mathrm{H}_{144} \mathrm{FeN}_{8} \mathrm{~S}_{4}$ : 1593.978 . FT-IR $\left(v, \mathrm{~cm}^{-1}\right)$ : 2918, 2850, 1601, 1494, 1466, 1392, 1324, 1261, 1187, 1143, 1073, 1037, 955, 915, 893, 817, 761, 743, 691. UV-vis $\left(\mathrm{CHCl}_{3}\right): \lambda \max$ $(\log \varepsilon): 710$ (4.8), 610 (4.1), 360 (4.7) nm.

\section{$\mu$-Nitrido-bis[tetra(n-}

butylthio)phthalocyaninato-iron] (3a). Monomeric iron phthalocyanine 2a (300 $\mathrm{mg}, 0.326 \mathrm{mmol})$ and sodium azide ( $1.7 \mathrm{~g}$ ) were refluxed overnight in degassed xylene (mixture of isomers) $(40 \mathrm{~mL})$ under argon with intensive stirring. The reaction mixture was cooled down to room temperature and the resulting blue green solution was filtrated to remove insoluble impurities. Xylene was then removed under reduced pressure and the crude product was purified by column chromotography on silica gel using a mixture of dichloromethane and ethanol, with an increasing polarity, starting from 50:1 to 10:1 ratio. Yield: $47 \%$ (143 mg). MALDITOF-MS (matrix DHB) $\mathrm{m} / \mathrm{z}: 1854.726$ [M]+; calcd for $\mathrm{C}_{96} \mathrm{H}_{96} \mathrm{Fe}_{2} \mathrm{~N}_{17} \mathrm{~S}_{8}:$ 1854.450. FT-IR $\left(v, \mathrm{~cm}^{-1}\right): 2954$, 2926, 2869, 1601, 1511, 1447, 1392, 1344, 1223, 1143, 1088, 1038, 962, 929 ( $\mathrm{Fe}-\mathrm{N}=\mathrm{Fe}), 897,815$, 764, 743, 691. Anal. calcd for $\mathrm{C}_{96} \mathrm{H}_{96} \mathrm{Fe}_{2} \mathrm{~N}_{17} \mathrm{~S}_{8} .7 \mathrm{H}_{2} \mathrm{O}$ : C, 58.17; H, 5.59; N, 12.01. Found: C, 58.30; H, 5.52; $\mathrm{N}, 12.21$. UV-vis $\left(\mathrm{CHCl}_{3}\right): \lambda \max (\log \varepsilon)=657$ (4.8), 602 (sh), 425 (4.5), 350 (4.7) nm.

\section{$\mu$-Nitrido-bis[tetra(tert-}

butylthio)phthalocyaninat-oiron] (3b). Monomeric iron phthalocyanine 2b $(273 \mathrm{mg}, 0.296 \mathrm{mmol})$ and sodium azide ( $1.5 \mathrm{~g}$ ) were refluxed overnight in degassed xylene (mixture of isomers) $(40 \mathrm{~mL})$ under argon with intensive stirring. The reaction mixture was cooled down to room temperature and the resulting blue green solution was filtrated to remove insoluble impurities. Xylene was removed under reduced pressure and the reaction crude purified by column chromotography on silica gel using a mixture of dichloromethane and ethanol, with an increasing polarity, starting from 50:1 to 10:1 ratio. Yield: $50 \%$ (138 mg). MALDI-TOF-MS (matrix DHB) $\mathrm{m} / \mathrm{z}:$ 1854.625[M]+; calcd for $\mathrm{C}_{96} \mathrm{H}_{96} \mathrm{Fe}_{2} \mathrm{~N}_{17} \mathrm{~S}_{8}:$ 1854.450. FT-IR $\left(\mathrm{v}, \mathrm{cm}^{-1}\right): 2958$, 2921, 2858, 1603, 1511, 1441, 1389, 1362, 1304, 1260, 1139, 1099, 1066, 1045, 962, 929 (Fe-N=Fe), 897, 828, 764, 746, 693. Anal. calcd for $\mathrm{C}_{96} \mathrm{H}_{96} \mathrm{Fe}_{2} \mathrm{~N}_{17} \mathrm{~S}_{8} .6 \mathrm{H}_{2} \mathrm{O}: \mathrm{C}, 58.70 ; \mathrm{H}, 5.54 ; \mathrm{N}, 12.12$. Found: C, 59.53; H, 6.10; N, 11.11. UV-vis $\left(\mathrm{CHCl}_{3}\right): \lambda$ $\max (\log \varepsilon)=648$ (4.9), 340 (5) nm.

\section{$\mu$-Nitrido-bis[tetra(iso-}

butylthio)phthalocyaninato-iron] (3c). Monomeric iron phthalocyanine 2c (473 $\mathrm{mg}, 0.514 \mathrm{mmol})$ and sodium azide ( $3 \mathrm{~g}$ ) were refluxed overnight in degassed xylene (mixture of isomers) (50 mL) under argon with intensive stirring. The reaction mix- ture was cooled down to room temperature and the resulting blue green solution was filtrated to remove insoluble impurities. Xylene was removed under reduced pressure and the reaction crude purified by column chromotography on silica gel using a mixture of dichloromethane and ethanol, with an increasing polarity, starting from 30:1 to 10:1 ratio. Yield: $27 \%$ (130 mg). MALDI-TOF-MS (matrix DHB) $\mathrm{m} / \mathrm{z}$ : $1855.744[\mathrm{M}+\mathrm{H}]^{+}$; calcd for $\mathrm{C}_{96} \mathrm{H}_{96} \mathrm{Fe}_{2} \mathrm{~N}_{17} \mathrm{~S}_{8}:$ 1854.450. FT-IR ( $\left.\mathrm{v}, \mathrm{cm}^{-1}\right): 2954$, 2926, 2868, 1602, 1511, 1446, 1384, 1365, 1344, $1310,1241,1141,1088,1069,1038,962,929$ (Fe$\mathrm{N}=\mathrm{Fe}$ ), 898, 814, 764, 743, 690. Anal. calcd for $\mathrm{C}_{96} \mathrm{H}_{96} \mathrm{Fe}_{2} \mathrm{~N}_{17} \mathrm{~S}_{8} .15 \mathrm{H}_{2} \mathrm{O}: \mathrm{C}, 54.23 ; \mathrm{H}, 5.97 ; \mathrm{N}, 11.20$. Found: $\mathrm{C}, 53.52 ; \mathrm{H}, 5.26 ; \mathrm{N}, 12.13$. UV-vis $\left(\mathrm{CHCl}_{3}\right): \lambda$ $\max (\log \varepsilon)=660$ (5.0), 345 (4.9) nm.

\section{$\mu$-Nitrido-bis[tetra(hexadecylthio)phthalo-} cyaninatoiron] (3d). Monomeric iron phthalocyanine $2 \mathbf{d}$ (524 $\mathrm{mg}, 0.342 \mathrm{mmol}$ ) and sodium azide (2 g) were refluxed overnight in degassed xylene (mixture of isomers) (80 $\mathrm{mL}$ ) under argon with intensive stirring. The reaction mixture was cooled down to room temperature and the resulting blue green solution was filtrated to remove insoluble impurities. Xylene was removed under reduced pressure and the reaction crude purified by column chromotography on silica gel using a mixture of dichloromethane and ethanol, with an increasing polarity, starting from 100:1 to 50:1 ratio. Yield: 49 $\%$ (270 mg). MALDI-TOF-MS (matrix DIT) $\mathrm{m} / \mathrm{z}$ : $3200.668[\mathrm{M}+\mathrm{H}]^{+}$; calcd for $\mathrm{C}_{192} \mathrm{H}_{288} \mathrm{Fe}_{2} \mathrm{~N}_{17} \mathrm{~S}_{8}$ : 3199.952. FT-IR ( $\left.v, \mathrm{~cm}^{-1}\right): 2920,2850,1603,1512$, 1455, 1395, 1345, 1311, 1260, 1200 1142, 1090, 1039, 930 ( $\mathrm{Fe}-\mathrm{N}=\mathrm{Fe}), 815,765,744,720$ 692. Anal. calcd for $\mathrm{C}_{192} \mathrm{H}_{288} \mathrm{Fe}_{2} \mathrm{~N}_{17} \mathrm{~S}_{8} .14 \mathrm{H}_{2} \mathrm{O}: \mathrm{C}, 66.75 ; \mathrm{H}, 9.22$; $\mathrm{N}, 6.89$. Found: C, 66.75; H, 10.05; N, 7.08. UV-vis $\left(\mathrm{CHCl}_{3}\right): \lambda \max (\log \varepsilon)=655$ (4.9), $349(4.9) \mathrm{nm}$.

\section{ASSOCIATED CONTENT}

Supporting Information. ${ }^{1} \mathrm{H}$ and ${ }^{13} \mathrm{C}$ NMR spectra and FT-IR spectrum of 1c, FT-IR, electronic absorption and MALDI-TOF spectra of 2a-d, electronic absorption, MALDI-TOF and ESR spectra of 3a-d, cyclic voltammogram of 3c, electronic absorption data of $\mathbf{3 c}$ in its different redox states, Raman spectra of $\mathbf{3 a}, \mathbf{3} \mathbf{b}$ and $\mathrm{LuPc}_{2}$ films, Raman data of $\mathbf{3 a}, \mathrm{LuPc}_{2}$ and $\mathbf{3 a} / \mathrm{LuPc}_{2}$.

The Supporting Information is available free of charge on the ACS Publications website.

\section{AUTHOR INFORMATION}

\author{
Corresponding Author \\ *E-mail: u.isci@gtu.edu.tr \\ * E-mail: marcel.bouvet@u-bourgogne.fr \\ ORCID
}

Marcel Bouvet: 0000-0002-2272-6633 
Fabienne Dumoulin: 0000-0002-0388-8338

Ümit İşci: 0000-0002-6285-0524

Rita Meunier-Prest: 0000-0001-5597-3879

Zeynel Şahin: 0000-0002-7719-7652

\section{Author Contributions}

The manuscript was written through contributions of all authors. All authors have given approval to the final version of the manuscript.

\section{Funding Sources}

No competing financial interests have been declared.

\section{ACKNOWLEDGMENT}

The Scientific and Technological Research Council of Turkey (TUBITAK) and the French Embassy in Turkey are gratefully acknowledged for the bilateral Partenariat Hubert Curien between Turkey and France (project Bosphorus 117Z623 / 39745WG). The authors acknowledge the Agence Nationale de la Recherche for funding through the ANR project OUTSMART ANR-2015-CE39-0004-03. Financial support from the European Union and the Conseil Régional de Bourgogne through the FABER and the PARI SMT 08 and CDEA programs is gratefully acknowledged. The Ministère de la Cohésion des Territoires et des Relations avec les Collectivités Territoriales (France) and the Conseil Régional de Bourgogne are thanked for the CPER.

\section{REFERENCES}

(1) Goedkent, V. L.; Ercolani, C. Nitrido-Bridged Iron Phthalocyanine Dimers: Synthesis and Characterization. J. Chem. Soc., Chem. Comm. 1984, 6, 378-379.

(2) Rossi, G.; Gardini, M.; Pennesi, G.; Ercolani, C.; Goedken, V. L. Notes. Ruthenium Phthalocyanine Chemistry: Synthesis and Properties of a MixedValence Nitrido-Bridged Ruthenium Phthalocyanine Dimer. J. Chem. Soc., Dalton Trans. 1989, 1, 193195.

(3) Verma, S.; Hanack, M. Synthesis of Nitrido (Phthalocyaninato) Metal (v) Complexes $\mathrm{R}_{n} \mathrm{PcMN}(\mathrm{M}=\mathrm{Re}, \mathrm{Mo}$, W) and New Compounds with Nitrido-Bridges Between Rhenium and Elements .... Z. Anorg. Allg. Chem. 2003, 629 (5), 880-892.

(4) Işci, U.; Dumoulin, F.; Sorokin, A. B.; Ahsen, V. NBridged Dimers of Tetrapyrroles Complexed by Transition Metals: Syntheses, Characterization Methods, and Uses as Oxidation Catalysts. Turkish J. Chem. 2014, 38 (6), 923-949.

(5) Kennedy, B. J.; Murray, K. S.; Homborg, H.; Kalz, W. Iron(IV)Phthalocyanines. Magnetic and Spectral Features of $\mu$-Nitrido-Iron-Phthalocyanine, (FePc)2N and of Some Oxidized Derivatives. Inorg. Chim. Acta 1987, 134 (1), 19-21.

(6) Donzello, M. P.; Ercolani, C.; Kadish, K. M.; Ou, A. Z.; Russo, U. Synthesis, Chemical-Physical Characterization, and Redox Properties of a New Mixed-Ligand Heterobimetallic N-Bridged Dimer: ( $\mu$ Nitrido)[((Tetraphenylporphyrinato)Manganese) ((Phthalocyaninato)Iron)]. Inorg. Chem. 1998, 37 (15), 3682-3688.

(7) Işci, U.; Afanasiev, P.; Millet, J.-M. M.; Kudrik, E. V.;
Ahsen, V.; Sorokin, A. B. Preparation and Characterization of $\mu$-Nitrido Diiron Phthalocyanines with Electron-Withdrawing Substituents: Application for Catalytic Aromatic Oxidation. Dalton Trans. 2009, 36, 74107420.

Kudrik, E. V.; Afanasiev, P.; Sorokin, A. B. Synthesis and Properties of FellI-N=MnIV Heterometallic Complex with Tetra-Tert-Butylphthalocyanine Ligands. Macroheterocycles 2010, 3, 19-22.

(9) Işci, U.; Faponle, A. S.; Afanasiev, P.; Albrieux, F.; Briois, V.; Ahsen, V.; Dumoulin, F.; Sorokin, A. B.; de Visser, S. P. Site-Selective Formation of an Iron(IV)Oxo Species at the More Electron-Rich Iron Atom of Heteroleptic $\mu$-Nitrido Diiron Phthalocyanines. Chem. Sci. 2015, 6 (8), 5063-5075.

(10) Colomban, C.; Kudrik, E. V.; Sorokin, A. B. Heteroleptic M-Nitrido Diiron Complex Supported by Phthalocyanine and Octapropylporphyrazine Ligands: Formation of Oxo Species and Their Reactivity with Fluorinated Compounds. J. Porphyrins Phthalocyanines 2017, 21 (04-06), 345-353.

(11) Moubaraki, B.; Benlian, D.; Baldy, A.; Pierrot, M.; IUCr. $\mu$-Nitruro-Bis[Bromo(Phtalocyaninato)Fer], (BrFePc)2N. Acta Crystallogr Sect C Cryst Struct Commun 1989, 45 (3), 393-394.

(12) Afanasiev, P.; Sorokin, A. B. $\mu$-Nitrido Diiron Macrocyclic Platform: Particular Structure for Particular Catalysis. Acc. Chem. Res. 2016, 49 (4), 583-593.

(13) Ercolani, C.; Gardini, M.; Pennesi, G.; Rossi, G. HighValent Iron Phthalocyanine. Mu.-Nitrido Dimers. Inorg. Chem. 1988, 27, 422-424.

(14) Işci, U.; Dumoulin, F.; Ahsen, V.; Sorokin, A. B. Preparation of $\mathrm{N}$-Bridged Diiron Phthalocyanines Bearing Bulky or Small Electron-Withdrawing Substituents. J. Porphyrins Phthalocyanines 2010, 14 (04), 324-334.

(15) Bottomley, L. A.; Gorce, J. N.; Goedken, V. L. Spectroelectrochemistry of a. Mu.-Nitrido-Bridged Iron Phthalocyanine Dimer. Inorg. Chem. 1985, 24, 37333737.

(16) Miller, D. R.; Akbar, S. A.; Morris, P. A. Nanoscale Metal Oxide-Based Heterojunctions for Gas Sensing: a Review. Sens. Actuators: B. Chem. 2014, 204, 250272.

(17) Hatchett, D. W.; Josowicz, M. Composites of Intrinsically Conducting Polymers as Sensing Nanomaterials. Chem. Rev. 2008, 108 (2), 746-769.

(18) Potje-Kamloth, K. Semiconductor Junction Gas Sensors. Chem. Rev. 2008, 108 (2), 367-399.

(19) Parra, V.; Bouvet, M. Semiconductor Transducer and Its Use in a Sensor for Detecting Electron-Donor or Electron-Acceptor Species, US8450725 B2, 2013. 8450725 ed.

(20) Parra, V.; Brunet, J.; Pauly, A.; Bouvet, M. Molecular Semiconductor-Doped Insulator (MSDI) Heterojunctions: an Alternative Transducer for Gas Chemosensing. Analyst 2009, 134 (9), 1776-1778.

(21) Bouvet, M.; Simon, J. Electrical Properties of Rare Earth Bisphthalocyanine and Bisnaphthalocyanine Complexes. Chem. Phys. Lett. 1990, 172 (3-4), 299302.

(22) Bouvet, M.; Gaudillat, P.; Kumar, A.; Sauerwald, T.; Schüler, M.; Schütze, A.; Suisse, J.-M. Revisiting the Electronic Properties of Molecular Semiconductor Doped Insulator (MSDI) Heterojunctions Through Impedance and Chemosensing Studies. Org. Electron. 2015, 26, 345-354.

(23) Zorlu, Y.; Kumru, U.; Işci, U.; Divrik, B.; Jeanneau, E.; Albrieux, F.; Dede, Y.; Ahsen, V.; Dumoulin, F. 1,4,8,11,15,18,22,25-Alkylsulfanyl Phthalocyanines: Effect of Macrocycle Distortion on Spectroscopic and Packing Properties. Chem. Commun. (Camb.) 2015, 
51 (30), 6580-6583.

(24) Timmer, B.; Olthuis, W.; Berg, A. V. D. Ammonia

Sensors and Their Applications-a Review. Sens. Actuators: B. Chem. 2005, 107 (2), 666-677.

(25) Lever, A. B. P.; Milaeva, E. R.; Speier, G. The Redox Chemistry of Metallophthalocyanines in Solution. In Phthalocyanines, Properties and Applications; Leznoff, C. C., Lever, A. B. P., Eds.; 1993; Vol. 3, pp $1-69$.

(26) Lexa, D.; Rentien, P.; Saveant, J. M.; Xu, F. Methods for Investigating the Mechanistic and Kinetic Role of Ligand Exchange Reactions in Coordination Electrochemistry: Cyclic Voltammetry of Chloroiron(III) Tetraphenylporphyrin in Dimethylformamide. J. Electroanal. Chem. 1985, 191 (2), 253-279.

(27) Mugnier, Y.; Moise, C.; Laviron, E. Electrochemical Studies of Organometallic Compounds : I. on the Reversibility of the First Reduction Stage of Titanocene Dichloride. J. Organomet. Chem. 1981, 204 (1), 6166.

(28) Mugnier, Y.; Moise, C.; Laviron, E. Electrochemical Studies on Organometallic Compounds : II. the Oxidation of Titanocene Monochloride. J. Organomet. Chem. 1981, 210 (1), 69-72.

(29) Kadish, K. M.; Rhodes, R. K.; Bottomley, L. A.; Goff, H. M. Inorg. Chem. 1981. Electrochemical and NMR Studies of Six-Coordinate Oxidized. Mu.-Nitrido Iron Porphyrin Dimers. Inorg. Chem.

(30) L'Her, M.; Pondaven, A. Electrochemistry of Phthalocyanines. In The Porphyrin Handbook; Kadish, K. M., Smith, K. M., Guilard, R., Eds.; Elsevier: Amsterdam, 2003; Vol. 16, pp 117-169.

(31) Mack, J.; Stillman, M. J. Assignment of the Optical Spectrum of Metal Porphyrin and Phthalocyanine Radical Anions. J. Porphyrins Phthalocyanines 2012 , $05(01), 67-76$.

(32) Sorokin, A. B. Phthalocyanine Metal Complexes in Catalysis. Chem. Rev. 2013, 113 (10), 8152-8191.

(33) Brédas, J. L.; Silbey, R.; Boudreaux, D. S.; Chance, R. R. Chain-Length Dependence of Electronic and Electrochemical Properties of Conjugated Systems: Polyacetylene, Polyphenylene, Polythiophene, and Polypyrrole. J. Am. Chem. Soc. 1983, 105 (22), 65556559.

(34) Cardona, C. M.; Li, W.; Kaifer, A. E.; Stockdale, D.; Bazan, G. C. Electrochemical Considerations for Determining Absolute Frontier Orbital Energy Levels of Conjugated Polymers for Solar Cell Applications. Adv. Mater. 2011, 23 (20), 2367-2371.

(35) Bouvet, M.; Silinsh, E. A.; Simon, J. Determination of Energy Gap Values in Molecular Crystals II. Intrinsic Dark Conductivity and Electrochemical Methods. Mol. Mater. 1995, 5, 255-277.

(36) Chen, Y.; Bouvet, M.; Sizun, T.; Gao, Y.; Plassard, C.; Lesniewska, E.; Jiang, J. Facile Approaches to Build Ordered Amphiphilic Tris(Phthalocyaninato) Europium Triple-Decker Complex Thin Films and Their Comparative Performances in Ozone Sensing. Phys. Chem.

Chem. Phys. 2010, 12 (39), 12851-11.
(37)

Bao, M.; Bian, Y.; Rintoul, L.; Wang, R.; Arnold, D. P.; Ma, C.; Jiang, J. Vibrational Spectroscopy of Phthalocyanine and Naphthalocyanine in Sandwich-Type (Na)Phthalocyaninato and Porphyrinato Rare Earth Complexes. Vibr. Spectrosc. 2004, 34 (2), 283-291.

(38) Mateos, M.; Meunier-Prest, R.; Heintz, O.; Herbst, F.; Suisse, J.-M.; Bouvet, M. Comprehensive Study of Poly(2,3,5,6-Tetrafluoroaniline): From Electrosynthesis to Heterojunctions and Ammonia Sensing. ACS Appl. Mater. Interfaces 2018, 10 (23), 19974-19986.

(39) Mateos, M.; Tchangaï, M.-D.; Meunier-Prest, R.; Heintz, O.; Herbst, F.; Suisse, J.-M.; Bouvet, M. Low Conductive Electrodeposited Poly(2,5-Dimethoxy aniline) as a Key Material in a Double Lateral Heterojunction, for Sub-Ppm Ammonia Sensing in Humid Atmosphere. ACS Sens. 2019, 4 (3), 740-747.

(40) Bouvet, M.; Mateos, M.; Wannebroucq, A.; Navarrete, E.; Llobet, E. Tungsten Oxide - Lutetium Bisphthalocyanine n-p-n HeteroJunction: From Nanomaterials to a New Transducer for Chemo-Sensing. J. Mater. Chem. C 2019, 7, 6448-6455.

(41) Chen, Y.; Bouvet, M.; Sizun, T.; Barochi, G.; Rossignol, J.; Lesniewska, E. Enhanced Chemosensing of Ammonia Based on the Novel Molecular Semiconductor-Doped Insulator (MSDI) Heterojunctions. Sens. Actuators: B. Chem. 2011, 155 (1), 165-173.

(42) Xu, C. N.; Miura, N.; Ishida, Y.; Matsuda, K.; Yamazoe, N. Selective Detection of NH3 Over NO in Combustion Exhausts by Using $\mathrm{Au}$ and $\mathrm{MoO} 3$ Doubly Promoted WO3 Element. Sens. Actuators: B. Chem. 2000, 65 (1-3), 163-165.

(43) Young, J. G.; Onyebuagu, W. Synthesis and Characterization of di-Disubstituted Phthalocyanines. Inorg. Chem. 1990, 55, 2155-2159.

(44) Kobayashi, N.; Ogata, H.; Nonaka, N.; Luk'yanets, E. A. Effect of Peripheral Substitution on the Electronic Absorption and Fluorescence Spectra of Metal- Free and Zinc Phthalocyanines. Chemistry 2003, 9 (20), 5123-5134.

(45) Dolotova, O. V.; Bundina, N. I.; Derkacheva, V. M.; Negrimovskii, V. M.; Minin, V. V.; Larin, G. M.; Kaliya, O. L.; Luk'yanets, E. A. Zh. Obshch. Khim. 1992, 62, 2064-2075.

(46) Kaipova, S.; Dinçer, H.; Altindal, A. Synthesis, Characterization, Conduction, and Dielectric Properties of Tetra tert-Butylsulfanyl Substituted Phthalocyanines. J. Coord. Chem. 2014, 68 (4), 717-731.

(47) Gürol, I.; Ahsen, V.; Bekaroğlu, Ö. Synthesis of Tetraalkylthio-Substituted Phthalocyanines and Their Complexation with $\mathrm{Ag} I$ and Pd II. J. Chem. Soc., Dalton Trans. 1994, 0 (4), 497-500.

(48) Clarisse, C.; Riou, M. T. Synthesis and Characterization of Some Lanthanide Phthalocyanines. Inorg. Chim. Acta 1987, 130 (1), 139-144.

(49) Gaudillat, P.; Wannebroucq, A.; Suisse, J.-M.; Bouvet, M. Bias and Humidity Effects on the Ammonia Sensing of Perylene Derivative/Lutetium Bisphthalocyanine MSDI Heterojunctions. Sens. Actuators: B. Chem. 2016, 222, 910-917. 